\title{
Deficiency of tumor suppressor NDRG2 leads to attention deficit and hyperactive behavior
}

\author{
Yan Li, ${ }^{1,2,3}$ Anqi Yin, ${ }^{1}$ Xin Sun, ${ }^{4}$ Ming Zhang, ${ }^{1,5}$ Jianfang Zhang, ${ }^{6}$ Ping Wang, ${ }^{4}$ Rougang Xie, ${ }^{1,2}$ Wen Li, ${ }^{1}$ Ze Fan, ${ }^{1}$ Yuanyuan Zhu, ${ }^{2}$ \\ Han Wang, ${ }^{7}$ Hailong Dong, ${ }^{1}$ Shengxi $\mathrm{Wu}^{2}{ }^{2}$ and Lize Xiong ${ }^{1}$ \\ 'Department of Anesthesiology and Perioperative Medicine, Institute of Neuroscience, ${ }^{3}$ Department of Biochemistry and Molecular Biology, and ${ }^{4}$ Department of Pediatrics, Xijing Hospital, Fourth Military \\ Medical University, Xi'an, Shaanxi, China. ${ }^{5}$ Ceneral Hospital of Chengdu Military Command, Chengdu, Sichuan, China. ${ }^{5}$ Department of Gynecology and Obstetrics, Xijing Hospital, Fourth Military Medical \\ University, Xi'an, Shaanxi, China. ${ }^{\top}$ School of Biology and Basic Medical Sciences, Medical College, Soochow University, Suzhou, Jiangsu, China.
}

\begin{abstract}
Attention-deficit/hyperactivity disorder (ADHD) is a prevalent psychiatric disorder in children. Although an imbalance of excitatory and inhibitory inputs has been proposed as contributing to this disorder, the mechanisms underlying this highly heterogeneous disease remain largely unknown. Here, we show that $\mathbf{N}$-myc downstream-regulated gene 2 (NDRC2) deficiency is involved in the development of ADHD in both mice and humans. Ndrg2-knockout ( $\mathrm{Ndrg}^{-/-}$) mice exhibited ADHD-like symptoms characterized by attention deficits, hyperactivity, impulsivity, and impaired memory. Furthermore, interstitial glutamate levels and excitatory transmission were markedly increased in the brains of $\mathrm{Ndrg}^{-/-}$mice due to reduced astroglial glutamate clearance. We developed an NDRG2 peptide that rescued astroglial glutamate clearance and reduced excitatory glutamate transmission in NDRG2-deficient astrocytes. Additionally, NDRG2 peptide treatment rescued ADHD-like hyperactivity in the $\mathrm{Ndrg} 2^{-/-}$mice, while routine methylphenidate treatment had no effect on hyperactivity in these animals. Finally, children who were heterozygous for rs1998848, a SNP in NDRG2, had a higher risk of ADHD than children who were homozygous for rs1998848. Our results indicate that NDRG2 deficiency leads to ADHD phenotypes and that impaired astroglial glutamate clearance, a mechanism distinct from the well-established dopamine deficit hypothesis for ADHD, underlies the resultant behavioral abnormalities.
\end{abstract}

\section{Introduction}

Attention-deficit/hyperactivity disorder (ADHD) is a heterogeneous disorder that affects 1 in 20 children and results in poor lifetime outcomes $(1,2)$. Males are approximately 3 to 4 times more likely to be diagnosed with ADHD than females $(2,3)$. This disorder is defined and characterized by inattention, hyperactivity, impulsivity, and cognitive dysfunction $(3,4)$. ADHD is commonly associated with dysfunctions in the dopaminergic neurotransmitter system (5, 6). However, ADHD susceptibility cannot be completely explained by the hypodopaminergic hypothesis $(7,8)$. These studies and the clinical heterogeneity reflect the existence of diverse neuropathological mechanisms underlying the development of ADHD.

Shared genetic architectures have been revealed in schizophrenia, autism, and ADHD (9-11), which could explain the overlap of abnormal behaviors in these psychiatric disorders. Recent studies have identified 14q11.2 as a potential psychiatric phenotype susceptibility locus (12-15). Human N-myc downstream-regulated gene 2 (NDRG2), a gene located at the $14 q 11.2$ locus $(16,17)$, was first discovered and cloned from brain tissues (18). The functions of NDRG2 in the central nervous system are still largely unknown, although NDRG2 has been well studied as a tumor suppressor.

Authorship note: Y. Li, A. Yin, X. Sun, and M. Zhang contributed equally to this work. Conflict of interest: The authors have declared that no conflict of interest exists. Submitted: April 7, 2017; Accepted: September 12, 2017.

Reference information: J Clin Invest. 2017;127(12):4270-4284.

https://doi.org/10.1172/JCI94455.
NDRG2 is primarily expressed in astrocytes in various brain areas, but not in neurons or microglia (19). There is growing evidence that NDRG2 is an early stage stress-response gene whose expression is upregulated under excitotoxic conditions in the brain, including ischemia (20), trauma (21), and Alzheimer's disease (22). Ndrg2-knockout ( $\left.N d r g 2^{--}\right)$mice were generated to evaluate the potential physiological and pathological roles of NDRG2.

We found that $\mathrm{Ndrg}^{-1-}$ mice exhibited typical ADHD-like behaviors, including hyperactivity, impulsivity, and inattention, as well as other abnormalities, such as impaired memory and enhanced $\theta$ electroencephalogram (EEG) rhythms. However, hyperactivity was not alleviated by methylphenidate, which is routinely prescribed for children with ADHD. In addition, increased excitatory transmission and dysfunctional astroglial glutamate clearance were observed in the $\mathrm{Ndrg}^{-/-}$mice. Based on these findings, we hypothesized that NDRG2 deficiency is associated with the development of ADHD through a nondopaminergic mechanism.

Here, we provide evidence strongly suggesting that rs1998848, a SNP in NDRG2, is associated with levels of NDRG2 expression and ADHD susceptibility. In addition, we show that impaired astroglial glutamate clearance, rather than dopaminergic deficits, underlies the NDRG2 deficiency-induced ADHD phenotype.

\section{Results}

Hyperactivity in $\mathrm{Ndrg2^{-/- }}$ mice. We generated $\mathrm{Ndrg} 2^{-/-}$mice by targeting exons 2-6 (Supplemental Figures 1 and 2; supplemental material available online with this article; https://oi.org/10.1172/ 
JCI94455DS1) to determine the potential physiological or pathological roles of NDRG2 in the brain. Two-month-old $\mathrm{Ndrg}^{-/-}$mice exhibited significantly increased locomotor activity in their individual home cages compared with their WT littermates over the course of 24 hours (Supplemental Figure 3). $\mathrm{Ndrg}^{-/-}$mice had much higher locomotor activity at night than during the day, which is consistent with their nocturnal nature $(23,24)$. We then examined mouse locomotor activities with the open-field test and found that the $\mathrm{Ndrg} 2^{-/}$mice showed a significant increase in total distance traveled (approximately 2-fold) and number of lines crossed (Figure 1, A and B). Similarly, the mean moving velocity of the $\mathrm{Ndrg}^{-/-}$mice was increased approximately 2-fold compared with that of the WT mice (Figure 1C). However, the $\mathrm{Ndrg}^{-{ }^{--}}$and WT mice spent similar amounts of time in the center region of the open field (Figure 1D), indicating that the $\mathrm{Ndrg} 2^{-/-}$mice displayed a hyperactivity phenotype without altered baseline anxiety. The specificity of this NDRG2 deficiency-induced hyperactivity was supported by its independence from other behaviors, including gait pattern (Supplemental Figure 4, A and B) and muscle strength in the hanging wire test (Supplemental Figure 4C). Interestingly, heterozygous ( $\left.\mathrm{Ndrg} 2^{+/-}\right)$mice exhibited normal locomotor activity in the open-field test (Supplemental Figure 5).

In addition, the hyperactive behavior of the $\mathrm{Ndrg} 2^{-/-}$mice was reduced with age. The $\mathrm{Ndrg} 2^{-/-}$mice did not show significant differences from WT mice in locomotor activity at 8 or 12 months (Supplemental Figure 6), suggesting that the NDRG2 deficiency may be related to self-curing psychiatric diseases, such as ADHD.

$\mathrm{Ndrg} 2^{-/}$mice display altered attention and impulsivity. We first investigated the attention and impulsivity of the $\mathrm{Ndrg} 2^{--}$mice with the 5-choice serial reaction time task (5-CSRTT) to evaluate whether the NDRG2-deficient mice exhibited ADHD-like symptoms $(25,26)$. The animals were trained on a visual detection task that required attentional engagement (Figure 1E). A response to the illuminated hole reflects attention (accurate response), whereas a premature response before a light appears suggests impulsivity (premature response). The $\mathrm{Ndrg} 2^{-/-}$mice exhibited fewer correct responses and a greater number of premature responses than their WT littermates (Figure 1, F and G).

The baseline performances of the $\mathrm{Ndrg} \mathrm{2}^{-/-}$and WT mice in the 5-CSRTT differed. The animals were subjected to a 6-step training schedule defined by specific criteria (Supplemental Table 1) to allow them to fully learn the task before the formal 5-CSRTT experiments occurred. However, only the WT mice met the target criteria in the subsequent challenges. The $\mathrm{Ndrg} 2^{--}$mice exhibited more incorrect and premature responses during the training process (Supplemental Figure 7, A and B) than the WT mice did, whereas the number of omitted responses was similar between the $\mathrm{Ndrg2^{-/- }}$ and WT mice (Supplemental Figure 7C).

Ndrg2 $2^{-1}$ mice exhibit impaired memory. Several animal models of ADHD exhibit cognitive deficits, such as impaired memory (27-29), which are consistent with the clinical symptoms of the multiple behavioral abnormalities in children with $\operatorname{ADHD}(30,31)$. Thus, we investigated both short- and long-term memory in the

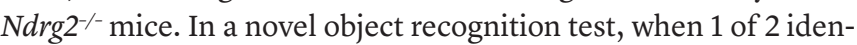
tical objects (familiar objects) was replaced with a new, differently shaped object (novel object) (Supplemental Figure 8A), the WT mice spent more time exploring the novel object than the familiar one at 1 hour and 24 hours after training, whereas the $\mathrm{Ndrg} 2^{-/-}$mice did not exhibit a preference for the novel object (Figure 1, H-J). The total amount of time spent exploring the identical objects in the familiar process was similar between the WT and $\mathrm{Ndrg} 2^{-/-}$mice (Supplemental Figure 8B). Therefore, the $\mathrm{Ndrg}^{-/-}$mice exhibited impairments in both short- and long-term memory.

Ndrg2 - mice with hyperactivity do not respond to methylphenidate. Canonical ADHD-associated hyperactivity should be alleviated by methylphenidate, a psychostimulant that increases dopamine release and is routinely used to treat $\operatorname{ADHD}(32,33)$. Surprisingly, the hyperactivity of the $\mathrm{Ndrg2^{-/- }}$ mice was not effectively suppressed by methylphenidate treatment (Supplemental Figure 9), suggesting that a unique neurobiological mechanism mediates NDRG2 deficiency-induced hyperactivity. Interestingly, approximately $35 \%$ of patients with ADHD do not respond to methylphenidate-like compounds $(34,35)$.

Enhanced $\theta$ EEG rhythms in the Ndrg2-/- mice. Children with ADHD and animal models of ADHD show increased $\theta$-band power in EEG $(28,36)$. Therefore, we recorded EEGs in WT and $\mathrm{Ndrg}^{-1-}$ mice. The $\theta$ rhythms were further analyzed in the range of 4 to 8 $\mathrm{Hz}$. The $\mathrm{Ndrg2^{-/- }}$ mice showed a substantially higher $\theta$ rhythm percentage in the total EEG in the frontal cortex than the WT mice (Figure 2, A and B).

Increased interstitial glutamate levels and excitatory transmission at $\mathrm{Ndrg}^{-1-}$ excitatory synapses. We analyzed the levels of neurotransmitters known to be associated with ADHD in the medial prefrontal cortex (mPFC), hippocampus, and striatum to characterize the pathophysiological mechanisms underlying NDRG2 deletion-induced ADHD-like behaviors. Notably, the concentrations of interstitial glutamate and aspartate were significantly higher in the mPFC, hippocampus, or striatum of the $\mathrm{Ndrg} 2^{-/-}$ mice than in the WT mice (Figure 2, C-E, and Supplemental Figure 10). However, the levels of dopamine, which are strongly associated with ADHD, as well as the levels of GABA, norepi-

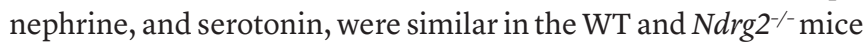
(Figure 2, C-E, and Supplemental Figure 10). These results may explain the failure of the methylphenidate treatment to reduce the hyperactivity of the $\mathrm{Ndrg2^{-/- }}$ mice.

Because glutamate is an important neurotransmitter in excitatory synaptic transmission, we investigated synaptic transmission in the mouse hippocampus. Spontaneous excitatory postsynaptic currents (sEPSCs) from CA1 pyramidal neurons of $\mathrm{Ndrg}^{-/-}$and WT mice were recorded. The $\mathrm{Ndrg} 2^{-/}$glutamatergic neurons exhibited a substantial increase in sEPSC amplitude compared with WT neurons. However, there were no differences in EPSC frequency between WT and KO neurons (Figure 2F). This enhancement of excitatory synaptic transmission is consistent with the increased interstitial glutamate levels in the $\mathrm{Ndrg}^{-/-}$mice.

Next, we determined whether glutamate receptor sensitivity to exogenous glutamate or glutamate receptor subtype expression

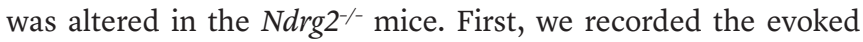
glutamate receptor-mediated excitatory postsynaptic currents (EPSCs) in the pyramidal neurons of striatum, hippocampus, and $\mathrm{mPFC}$ with exogenous glutamate $(25 \mu \mathrm{M})$ stimulation (Supplemental Figure 11, A, D, and G). Compared with baseline, glutamate treatment markedly enhanced EPSC amplitude in the striatum and hippocampus (Supplemental Figure 11, B, C, E, and 
A

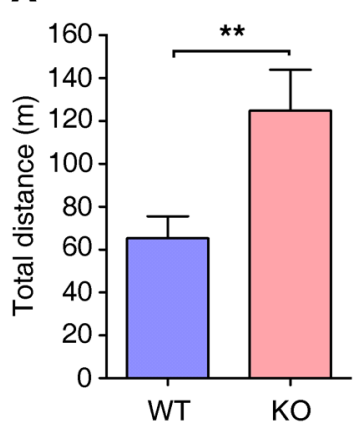

B

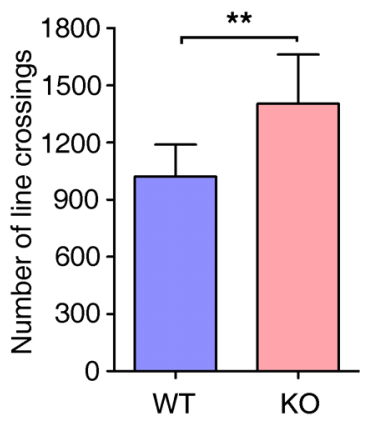

C

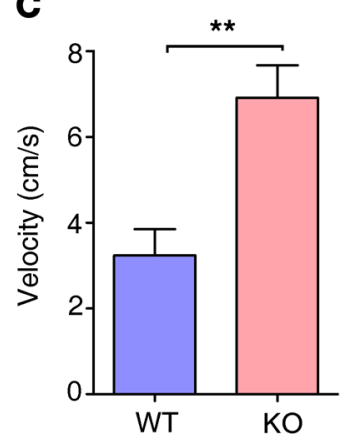

D

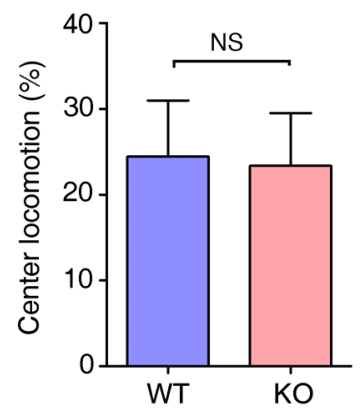

E

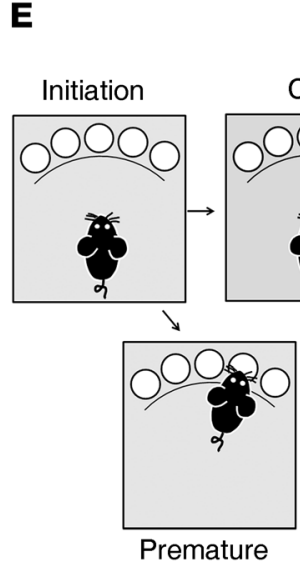

$\mathbf{F}$

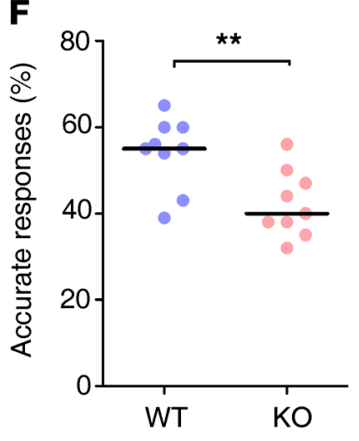

G

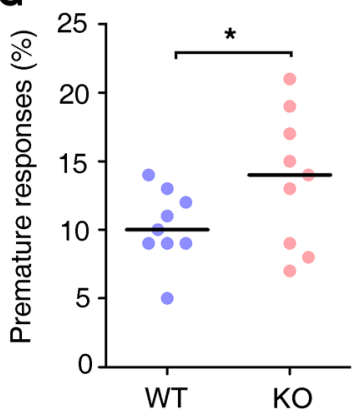

H

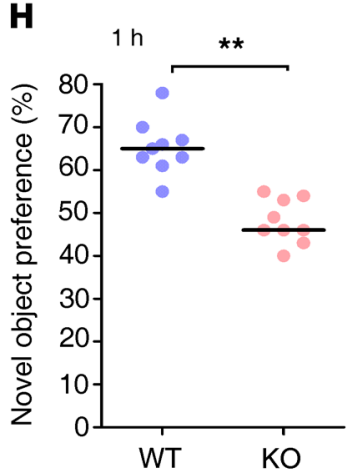

I

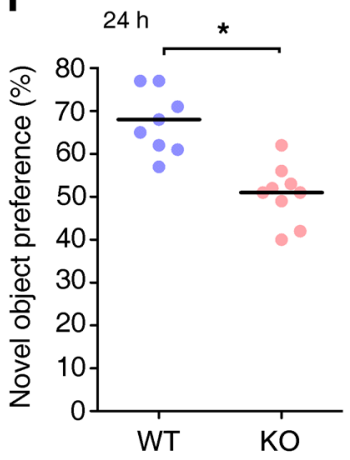

J

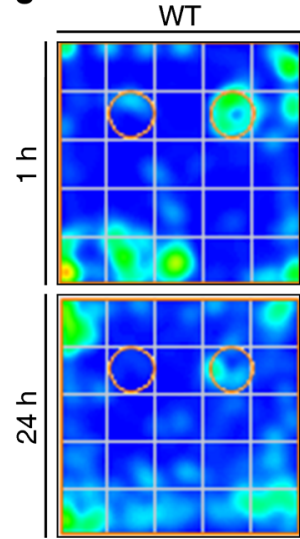

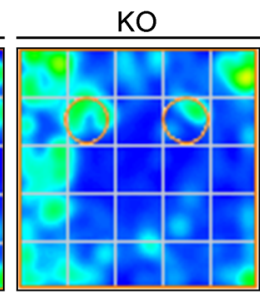

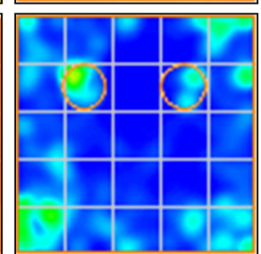

Figure 1. Ndrg2-/- mice display ADHD-like symptoms. (A-D) The locomotor activity of 2-month-old WT and Ndrg2/- mice in an open field is presented as the total distance traveled (A), number of lines crossed (B), velocity (C), and locomotion in the center of the field (D). $n=10 \mathrm{KO} ; n=9 \mathrm{WT}$. **P $<0.01$, Student's $t$ test. (E-G) Attention and impulsivity were detected in the WT and Ndrg2 $2^{-/-}$mice with a visual 5-CSRTT (E) and are represented by the accuracy percentage (F) and premature response percentage (G), respectively. $n=9 \mathrm{KO} ; n=9$ WT. ${ }^{*} P<0.05 ;{ }^{*} P<0.01$, Wilcoxon's rank sum test. (H-J) The shortterm $(\mathbf{H})$ and long-term $(\mathbf{I})$ memory of the WT and $\mathrm{Ndrg}^{-1-}$ mice were examined with the novel object recognition test. (J) Heatmaps show the time spent exploring both familiar and novel objects. The circles represent the objects' locations. $n=9 \mathrm{KO} ; n=9$ WT. ${ }^{*} P<0.05 ;{ }^{*} P<0.01$, Wilcoxon's rank sum test. Error bars indicate mean \pm SEM $(\mathbf{A}-\mathbf{D})$. Horizontal bars indicate medians $(\mathbf{F}-\mathbf{I})$.

F). However, there were no differences in enhancement of EPSC amplitude between WT and KO mice. In addition, the EPSC amplitude was consistent with or without glutamate stimulation in the mPFC in both the WT and KO mice (Supplemental Figure 11, $\mathrm{H}$ and I). Second, we investigated the expression levels of 2 major ionotropic glutamate receptors, NMDA receptors (NMDARs) and $\alpha$-amino-3-hydroxy-5-methyl-4-isoxazole propionic acid receptors (AMPARs), in the synaptosomes of the hippocampus in the $N d r g 2^{-/-}$and WT mice. The surface and total levels of NR1/NR2A/
NR2B (subunits of NMDARs) and GluR1/GluR2/GluR3 (subunits of AMPARs) were similar between the $N d r g 2^{-/-}$and WT mice (Supplemental Figure 12). Together, these data suggest that the increased interstitial glutamate levels induced by NDRG2 deficiency caused no changes in glutamate receptor subtype expression or receptor sensitivity to exogenous ligand stimulation. Note that, compared with the WT mice, the $\mathrm{Ndrg} 2^{-/-}$mice exhibited an approximately 4 -fold to 5 -fold increase in interstitial glutamate (Figure 2, C-E). We speculate that the increased interstitial glu- 
A

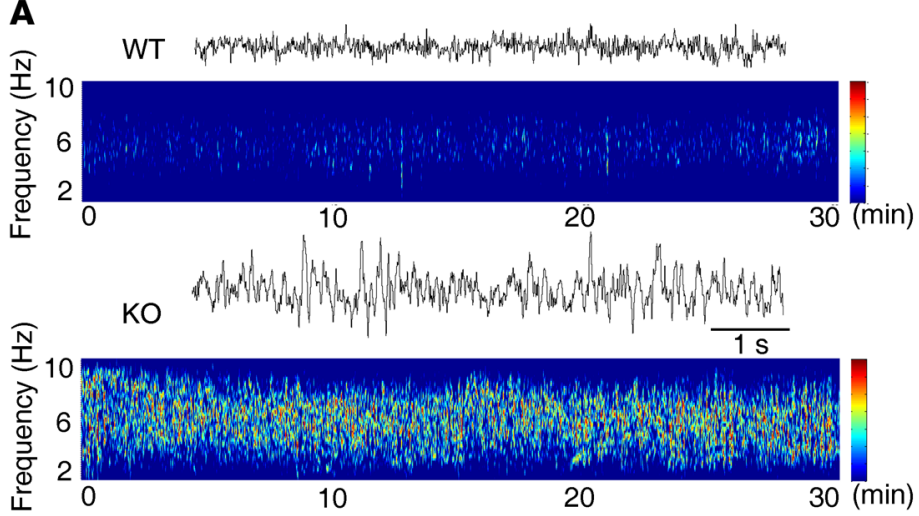

B

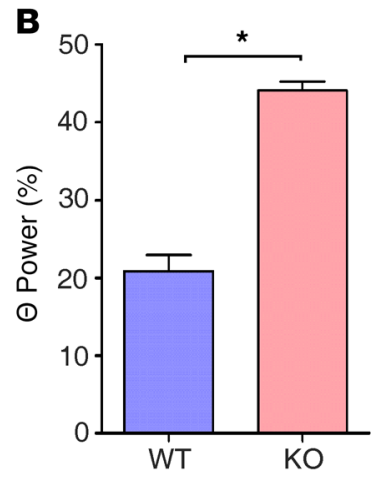

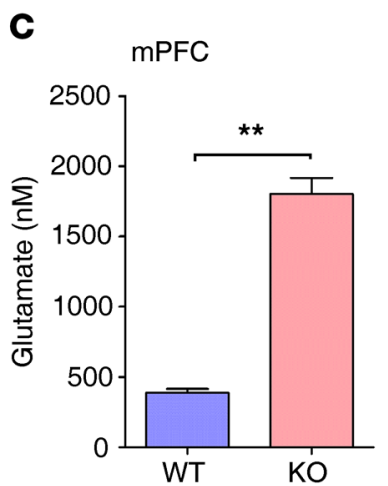

$\mathbf{E}$

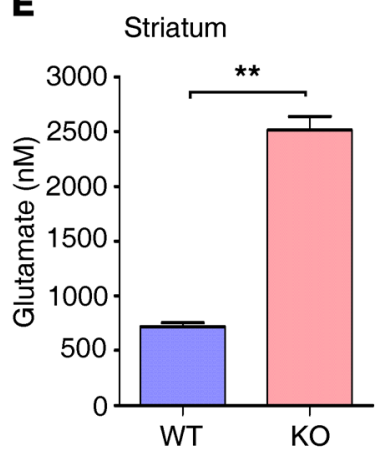

mPFC

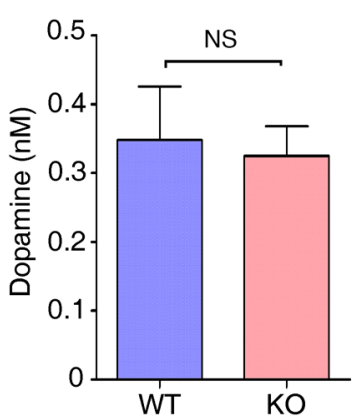

Striatum

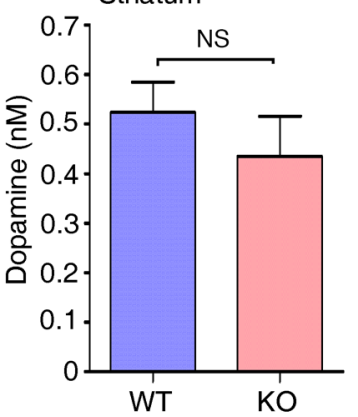

D
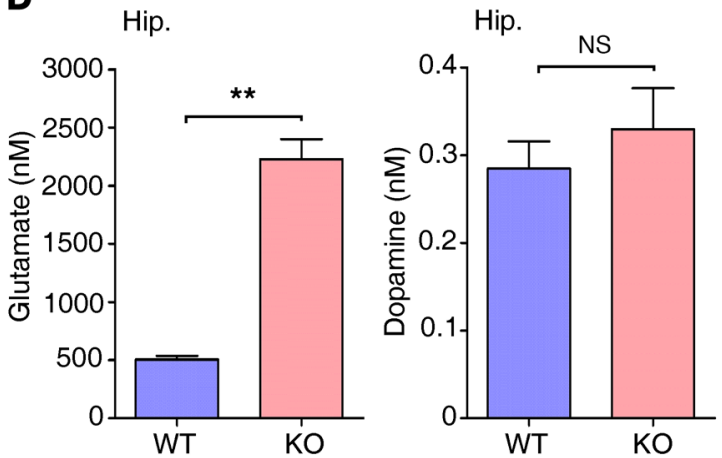

$\mathbf{F}$

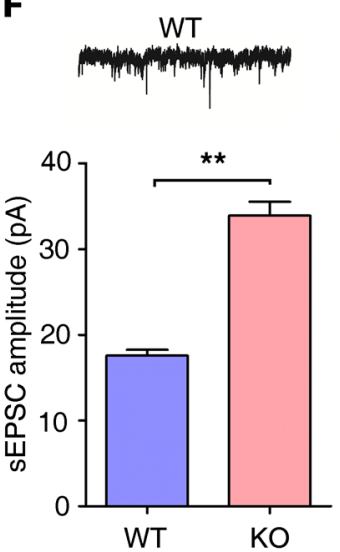

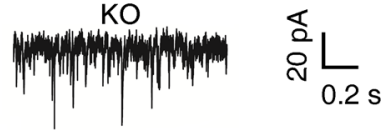

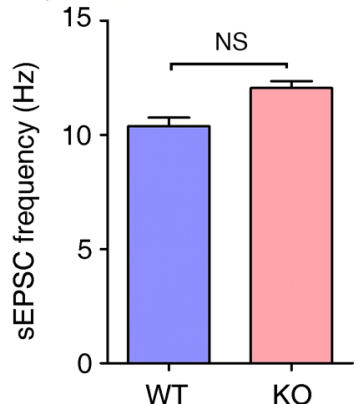

Figure 2. Enhanced excitatory transmission in the $\mathbf{N d r g}^{-/-}$brain. (A) Representative traces and spectrogram of $\theta$ EEG rhythms in WT and Ndrg2 $2^{-/-}$mice.

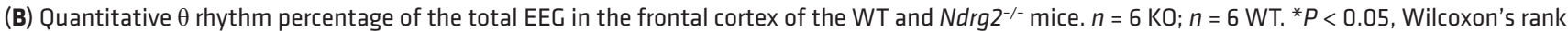
sum test. (C-E) Measurements of interstitial glutamate and dopamine concentrations in the MPFC (C), hippocampus (Hip.) (D), or striatum (E) of WT and $N d r g 2^{-1-}$ mice. $n=6$ per group. ${ }^{* *} P<0.01$, Student's $t$ test. (F) Representative sEPSC recordings in the WT and Ndrg2 $2^{-1-}$ hippocampal CA1 pyramidal neurons (upper trace). Amplitudes and frequencies of the sEPSCs (lower histogram, left and right, respectively) were quantified. $n=12$ per group. ${ }^{* *} P<0.01$, Student's $t$ test. Error bars indicate mean \pm SEM.

tamate activated glutamatergic neurons, but not to an extent that was sufficient to alter glutamate receptor expression or receptor sensitivity in the $\mathrm{Ndrg}^{-}$mice.

Given that the hyperactive behavior of the $\mathrm{Ndrg}^{--}$mice was reduced with age (Supplemental Figure 6), we further investigated the levels of interstitial glutamate and glutamate receptor subtype expression in the $\mathrm{Ndrg}^{2--}$ mice at 8 months. Unexpectedly, the levels of interstitial glutamate were still notably higher in the MPFC, hippocampus, and striatum of the $\mathrm{Ndrg}^{--}$mice than in the WT mice at 8 months (Supplemental Figure 13, A-C). However, we found a signif- icant decrease in NMDARs and AMPARs on the synaptic surface in the Ndrg2-- hippocampus compared with those in the WT hippocampus at 8 months (Supplemental Figure 13, D and E). These results suggest that the spontaneous reduction with age in hyperactivity in the $\mathrm{Ndrg}^{2-}$ mice depends on the decreased glutamate receptor expression rather than on an alteration in interstitial glutamate levels.

Astroglial NDRG2 is required for interstitial glutamate clearance. NDRG2 is mainly expressed in astrocytes, but not in neurons or microglia (Supplemental Figure 14), and astrocytes are the predominant cell type contributing to the clearance of glutamate from the 
A

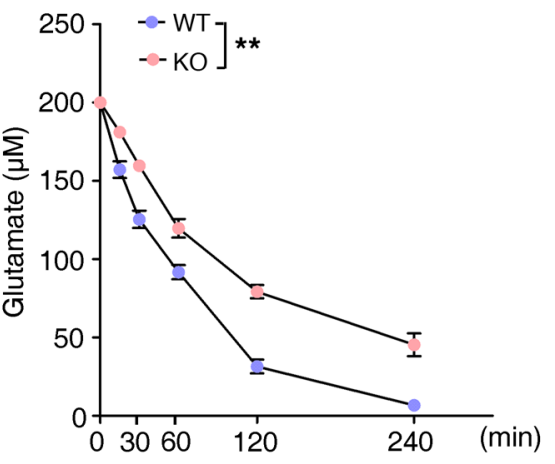

C

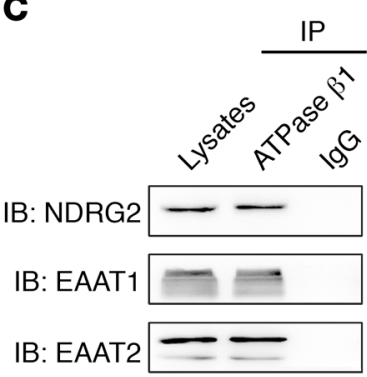

D
IB: ATPase $\beta 1$

IB: EAAT

IB: EAAT2
B

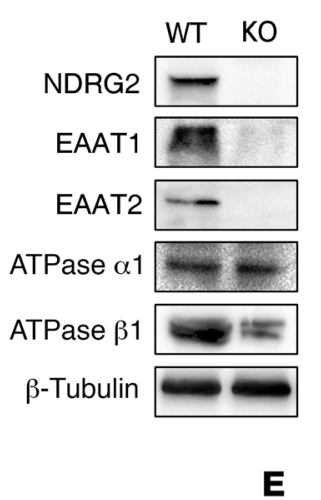

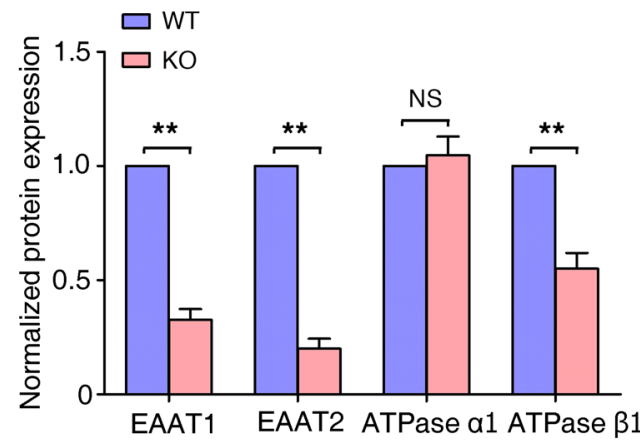

F

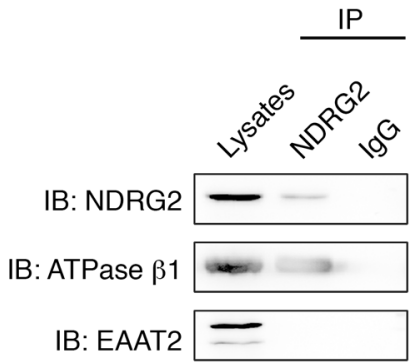

IB: EAAT2

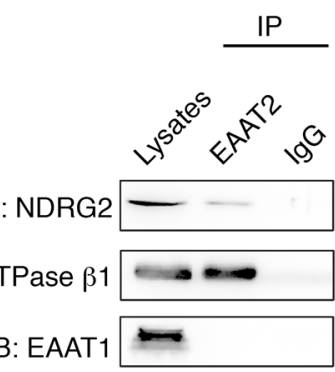

G

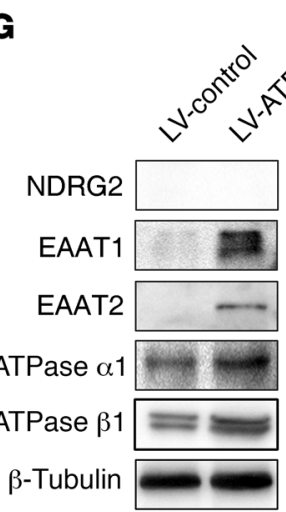

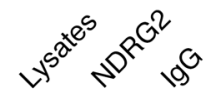

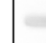

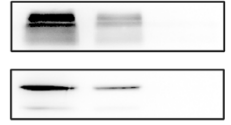

\section{H}

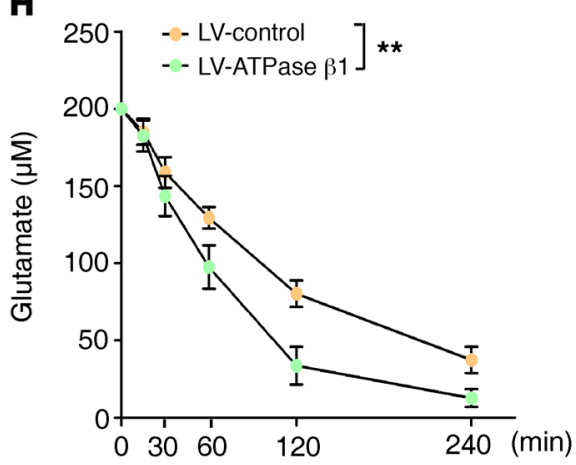

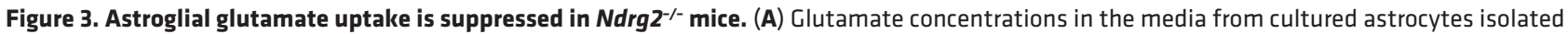
from WT or $\mathrm{Ndrg}^{---}$mice were measured at various time intervals. Data were obtained from 3 independent measurements, and each experiment was performed in quadruplicate. ${ }^{* *} P<0.01$, repeated-measures ANOVA. (B) Levels of the glutamate uptake-associated proteins NDRC2, EAAT1, EAAT2, Na ${ }^{+} /$ $\mathrm{K}^{+}$-ATPase $\alpha 1$ (ATPase $\alpha 1$ ), and $\mathrm{Na}^{+} / \mathrm{K}^{+}$-ATPase $\beta 1$ (ATPase $\beta 1$ ) in WT and $\mathrm{Ndrg} 2^{-/-}$astrocytes were analyzed by densitometry of immunoblots of whole-cell lysates and normalized to $\beta$-tubulin. Representative immunoblots from 3 independent experiments are shown. ${ }^{*} P<0.01$, Student's $t$ test. Error bars indicate mean \pm SEM. (C-F) Analysis of the coimmunoprecipitation of the NDRG2, EAAT1/EAAT2, and Na ${ }^{+} / K^{+}-A T P a s e ~ \beta 1$ proteins in the WT astrocytes using antibodies specific to $\mathrm{Na}^{+} / \mathrm{K}^{+}-$ATPase $\beta 1$ (C), NDRC2 (D), EAAT1 (E), or EAAT2 (F) as the precipitation antibody. Representative immunoblots from 3 independent experiments are shown. (C) Levels of NDRG2, EAAT1, EAAT2, $\mathrm{Na}^{+} / \mathrm{K}^{+}-$ATPase $\alpha 1$ (ATPase $\alpha 1$ ), and $\mathrm{Na}^{+} / \mathrm{K}^{+}-$ATPase $\beta 1$ (ATPase $\beta 1$ ) in the $\mathrm{Ndrg}^{-/}$ astrocytes infected with control lentivirus (LV-control) or $\mathrm{Na}^{+} / \mathrm{K}^{+}-A T P a s e ~ \beta 1$ lentivirus (LV-ATPase $\beta 1$ ). Representative immunoblots from 3 independent experiments are shown. ${ }^{* *} P<0.01$, Student's $t$ test. Error bars indicate mean $\pm \mathrm{SEM}$. (H) Glutamate concentrations in the media from cultured $\mathrm{Ndrg} 2^{-1-}$ astrocytes infected with control lentivirus or $\mathrm{Na}^{+} / \mathrm{K}^{+}$-ATPase $\beta 1$ lentivirus were measured at various time intervals. Data were obtained from 3 independent measurements, and each experiment was performed in quadruplicate. ${ }^{* *} P<0.01$, repeated-measures ANOVA.

synaptic space. To further explore the accumulation of interstitial glutamate at the $\mathrm{Ndrg}^{2-}$ excitatory synapses, we investigated the glutamate clearance ability of the $\mathrm{Ndrg}^{-\digamma}$ astrocytes. We isolated astrocytes from mouse brains and found that the rate and amount of glutamate uptake were significantly lower in the $\mathrm{Ndrg} 2^{--}$astrocytes than in the WT astrocytes at various time intervals (Figure 3A).

Interstitial glutamate in the brain is largely taken up by excitatory amino acid transporter 1 (EAAT1) and EAAT2, which are mainly expressed in astrocytes (37). The functions of EAAT1 and EAAT2 are driven by the transmembrane $\mathrm{Na}^{+}$gradient. The ion pump $\mathrm{Na}^{+} / \mathrm{K}^{+}$-ATPase maintains the $\mathrm{Na}^{+}$gradient by exporting $3 \mathrm{Na}^{+}$and importing $2 \mathrm{~K}^{+}$ions (38). We examined the expression levels of the molecules that participate in this process to determine the mechanism by which NDRG2 regulates interstitial glutamate clearance. Immunoblot analysis revealed that the levels of the EAAT1, EAAT2, and $\mathrm{Na}^{+} / \mathrm{K}^{+}$-ATPase $\beta 1$ proteins, but not $\mathrm{Na}^{+} / \mathrm{K}^{+}$-ATPase $\alpha 1$, were notably decreased in the cultured $\mathrm{Ndrg}^{--}$astrocytes (Figure 3B). We also found 
A

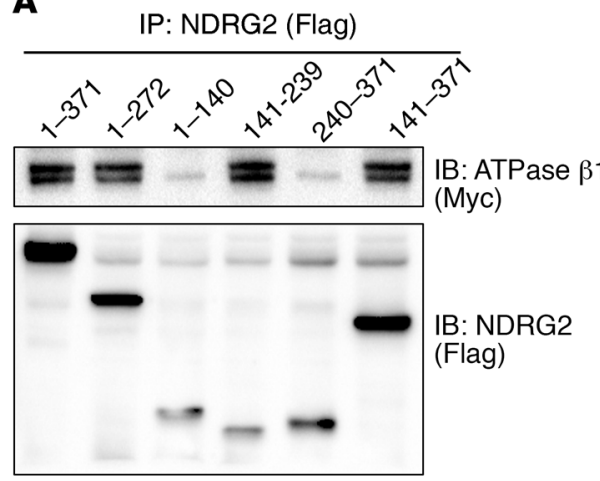

B

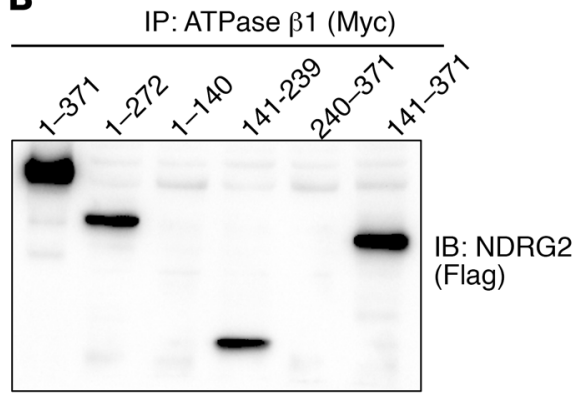

C

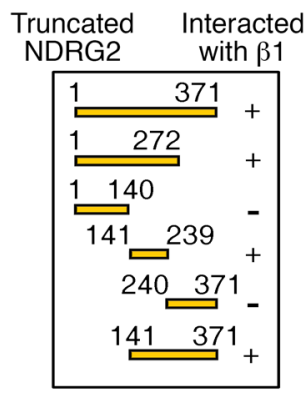

D

TAT-control

YGRKKRRQRRReakemlyfealvieqppasn

TAT-NDRG2(aa 141-160)

YGRKKRRQRRRigvgvgagayilsryalnhp

TAT-NDRG2(aa 161-180)

YGRKKRRQRRRdtveglvlinidpnakgwmd

TAT-NDRG2(aa 181-200)

YGRKKRRQRRRwaahkltgltssipdmilgh

TAT-NDRG2(aa 201-220)

YGRKKRRQRRRlfsqeelsgnseliqkyrgi

TAT-NDRG2(aa 221-239)

YGRKKRRQRRRiqhapnlenielywnsynn
E

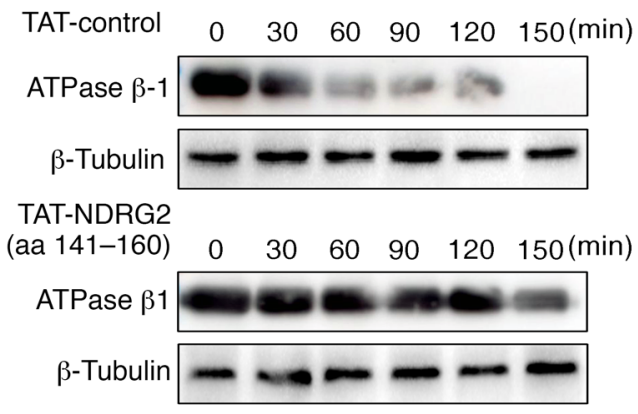

IB: ATPase $\beta 1$ (Myc)

$\mathbf{F}$

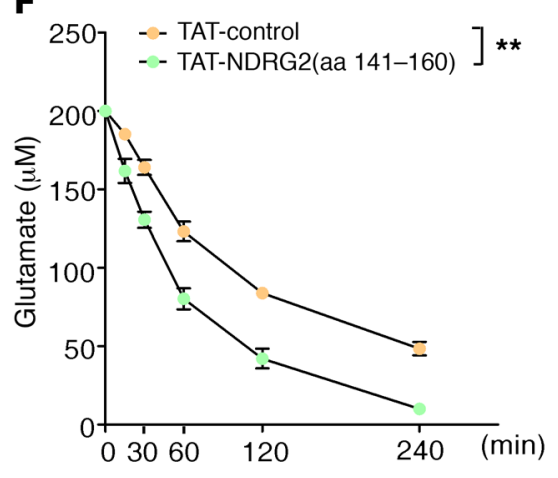

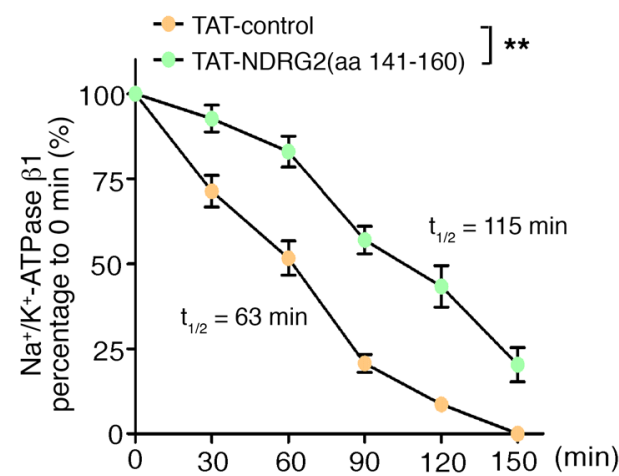

G

TAT-control TAT-NDRG2(aa 141-160)
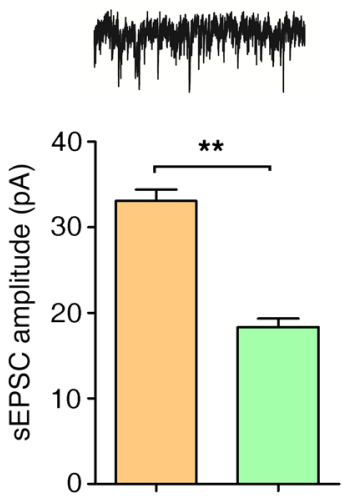
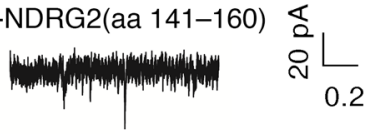

$0.2 \mathrm{~s}$

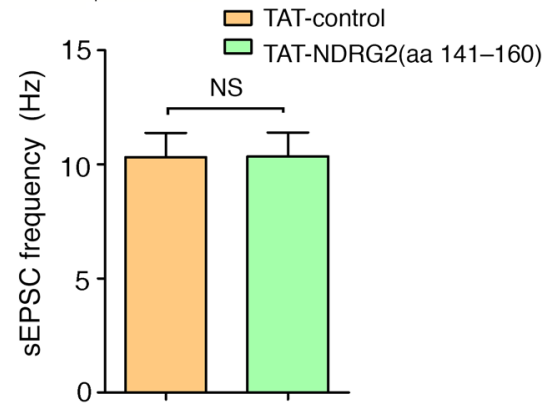

Figure 4. An NDRG2 peptide increases $\mathrm{Na}^{+} / \mathrm{K}^{+}-\mathrm{ATPase} \boldsymbol{\beta 1}$ stability and rescues the suppression of glutamate uptake in $\mathrm{Ndrg}^{2 /-}$ astrocytes. (A-C) Coimmunoprecipitation of Flag-tagged full-length NDRG2 (aa 1-371) and its different truncation mutants (aa 1-272, 1-140, 141-239, 240-371, and 141-371) with Myc-tagged full-length $\mathrm{Na}^{+} / \mathrm{K}^{+}$-ATPase $\beta 1$ in HEK293 cell lysates using Flag (A) or Myc (B) as the precipitation antibody. Representative immunoblots from 3 independent experiments are shown. (C) Schematic and results of the interactions. (D) NDRG2 peptides TAT-NDRG2(aa 141-160), TAT-NDRG2(aa 161-180), TAT-NDRG2 (aa 181-200), TAT-NDRG2(aa 201-220), TAT-NDRG2(aa 221-239), and the TAT-control peptide with a scrambled sequence. (E) Na/ $\mathrm{K}^{+}$-ATPase $\beta 1$ expression kinetics in the $\mathrm{Ndrg}^{-{ }^{--}}$astrocytes following the administration of the TAT-control or TAT-NDRG2(aa 141-160) peptide with emetine (a protein synthesis inhibitor). Representative immunoblots (left) from 3 independent experiments are shown. Relative $\mathrm{Na}^{+} / \mathrm{K}^{+}$-ATPase $\beta 1$ levels normalized to the $\beta$-tubulin levels were quantified by densitometry at various time intervals (right). ${ }^{*} P<0.01$, repeated-measures ANOVA. (F) Glutamate levels in the media of cultured $\mathrm{Ndrg}^{-/-}$astrocytes were measured at various time intervals following the administration of the TAT-control or TAT-NDRG2(aa 141-160) peptide. Data were obtained from 3 independent measurements, and each experiment was performed in quadruplicate. ${ }^{* *} P<0.01$, repeated-measures ANOVA.

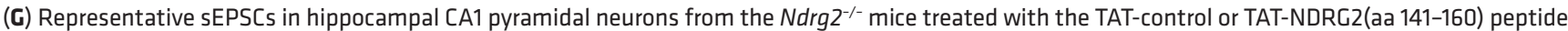
(upper trace). The amplitudes and frequencies of the sEPSCs (bottom histogram, left and right, respectively) were quantified. $n=12$ per group; ${ }^{* *} P<0.01$, Student's $t$ test. Error bars indicate mean \pm SEM $(\mathbf{E}-\mathbf{C})$.

decreased EAAT1, EAAT2, and $\mathrm{Na}^{+} / \mathrm{K}^{+}$-ATPase $\beta 1$ expression in the $\mathrm{mPFC}$, hippocampus, and striatum in the $\mathrm{Ndrg2^{-/- }}$ mice (Supplemental Figure 15). Thus, the stability of $\mathrm{Na}^{+} / \mathrm{K}^{+}-$ ATPase $\beta 1$ requires NDRG2 expression, which is consistent with our previous report showing that NDRG2 inhibited the ubiquitination and degradation of $\mathrm{Na}^{+} / \mathrm{K}^{+}$-ATPase $\beta 1$ (39).
$\mathrm{Na}^{+} / \mathrm{K}^{+}$-ATPase and EAAT1/2 are physically associated with a single macromolecular complex in the plasma membrane $(40,41)$. Therefore, we speculated that a dynamic NDRG2- $\mathrm{Na}^{+} / \mathrm{K}^{+}$-ATPase $\beta 1$-EAAT1/2 complex is required for the normal expression and function of EAAT1/2 in astrocytes. Using an anti- $\mathrm{Na}^{+} / \mathrm{K}^{+}$-ATPase $\beta 1$-specific antibody, NDRG2, EAAT1, or EAAT2 proteins were 
A
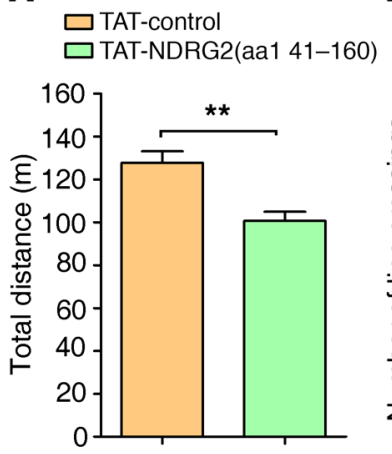

E

$$
\begin{aligned}
& 1 \mathrm{~h} \\
& \text { TAT-control } \\
& \text { TAT-NDRG2(aa 141-160) }
\end{aligned}
$$

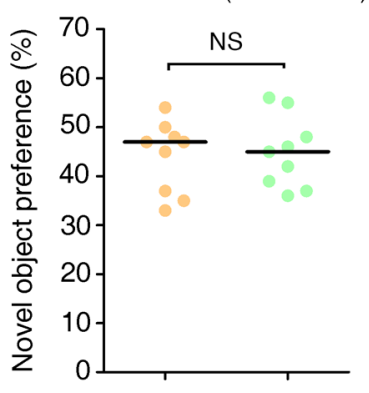

B

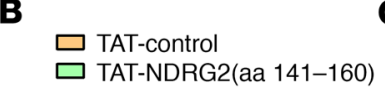

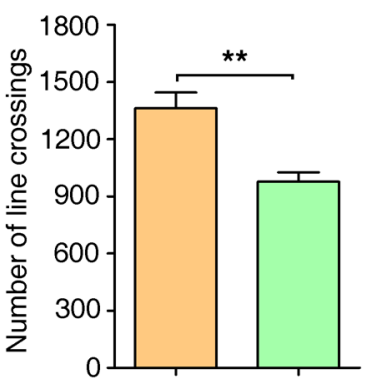

$\mathbf{F}$ $24 \mathrm{~h}$

- TAT-control

TAT-NDRG2(aa 141-160)

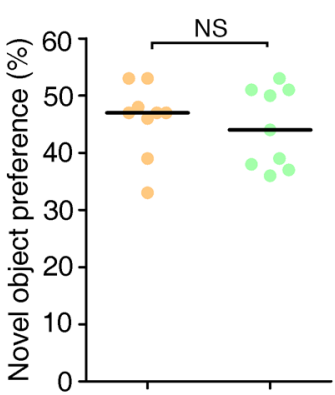

C DAT-control D TAT-NDRG2(aa 141-160) TAT-NDRG2(aa 141-160)

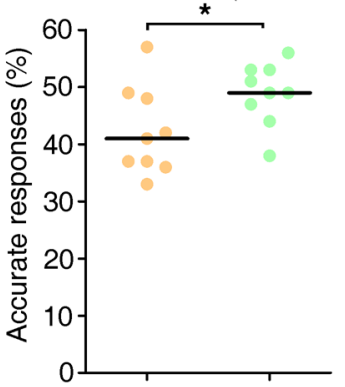

G

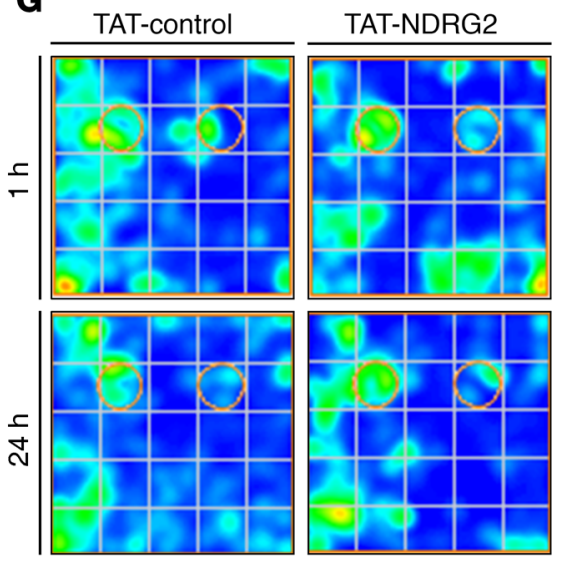

H



I
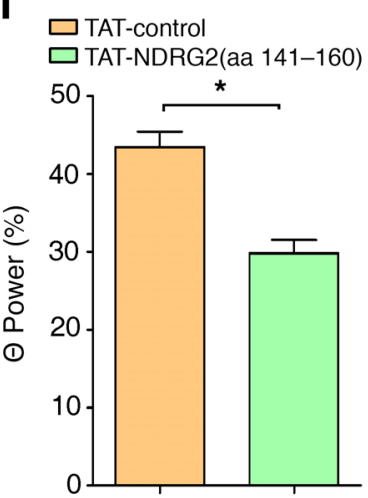

Figure 5. NDRG2 peptide corrects ADHD-like behaviors in $\mathbf{N d r g}^{-/-}$mice. (A, B) The locomotor activity of $\mathrm{Ndrg}^{-/-}$mice that were intravenously injected with TAT-control or TAT-NDRG2 (aa 141-160) is presented as the total distance traveled (A) and number of lines crossed (B). $n=9$ TAT-control; $n=9$ TAT-NDRG2(aa 141-160); ${ }^{* *} P<0.01$; Student's $t$ test. (C-D) Attention and impulsivity were detected in Ndrg2 ${ }^{-1-}$ mice following TAT-control or TAT-NDRG2(aa 141-160) injections and are presented as accuracy percentages (C) and premature response percentages (D), respectively. $n=9$ TAT-control; $n=9$ TAT-NDRG2(aa 141-160). ${ }^{*} P<0.05$, Wilcoxon's rank sum test. (E-C) Short-term (E) and long-term memory (F) of the Ndrg $2^{-1-}$ mice was assessed using the novel object recognition task after the administration of the TAT-control or TAT-NDRG2(aa 141-160) peptide. (C) Heatmaps of the results of the novel object recognition test. $n=9$ per group. Wilcoxon's rank sum test. (H) Representative traces and spectrogram of $\theta$ EEG rhythms in Ndrg2 $2^{-/-}$mice. (I) Quantitative $\theta$ rhythm percentage of total EEG in the frontal cortex of $\mathrm{Ndrg} 2^{-1-}$ mice following TAT-control or TAT-NDRG2(aa 141-160) injections. $n=6$ per group. ${ }^{*} P<0.05$, Wilcoxon's rank sum test.

Horizontal bars indicate medians (C-F). Error bars indicate mean \pm SEM (A, B, I).

precipitated (Figure 3C). In addition, proteins associated with $\mathrm{Na}^{+} /$ $\mathrm{K}^{+}$-ATPase $\beta 1$, EAAT1, or EAAT2 were individually precipitated with an anti-NDRG2 antibody (Figure 3D). Interactions among NDRG2, $\mathrm{Na}^{+} / \mathrm{K}^{+}$-ATPase $\beta 1$, and EAAT1/2 were also detected in the EAAT1 or EAAT2 antibody-precipitated complex (Figure 3, E and $F$ ). Thus, we speculated that $\mathrm{Na}^{+} / \mathrm{K}^{+}$-ATPase $\beta 1$ is required for the normal expression and function of EAAT1/2. To confirm the function of $\mathrm{Na}^{+} / \mathrm{K}^{+}$-ATPase $\beta 1$ in astroglial EAAT1/2 expression and glutamate uptake, we used a lentivirus system to overexpress $\mathrm{Na}^{+} / \mathrm{K}^{+}$-ATPase $\beta 1$ in cultured $\mathrm{Ndrg} 2^{-/-}$astrocytes. The expression levels of EAAT1 and EAAT2 were recovered by restoring the $\mathrm{Na}^{+}$/ $\mathrm{K}^{+}$-ATPase $\beta 1$ protein levels (Figure $3 \mathrm{G}$ ). Glutamate clearance was also markedly rescued after the overexpression of exogenous $\mathrm{Na}^{+}$/ $\mathrm{K}^{+}$-ATPase $\beta 1$ in the $\mathrm{Ndrg} 2^{-/-}$astrocytes (Figure $3 \mathrm{H}$ ). 
A
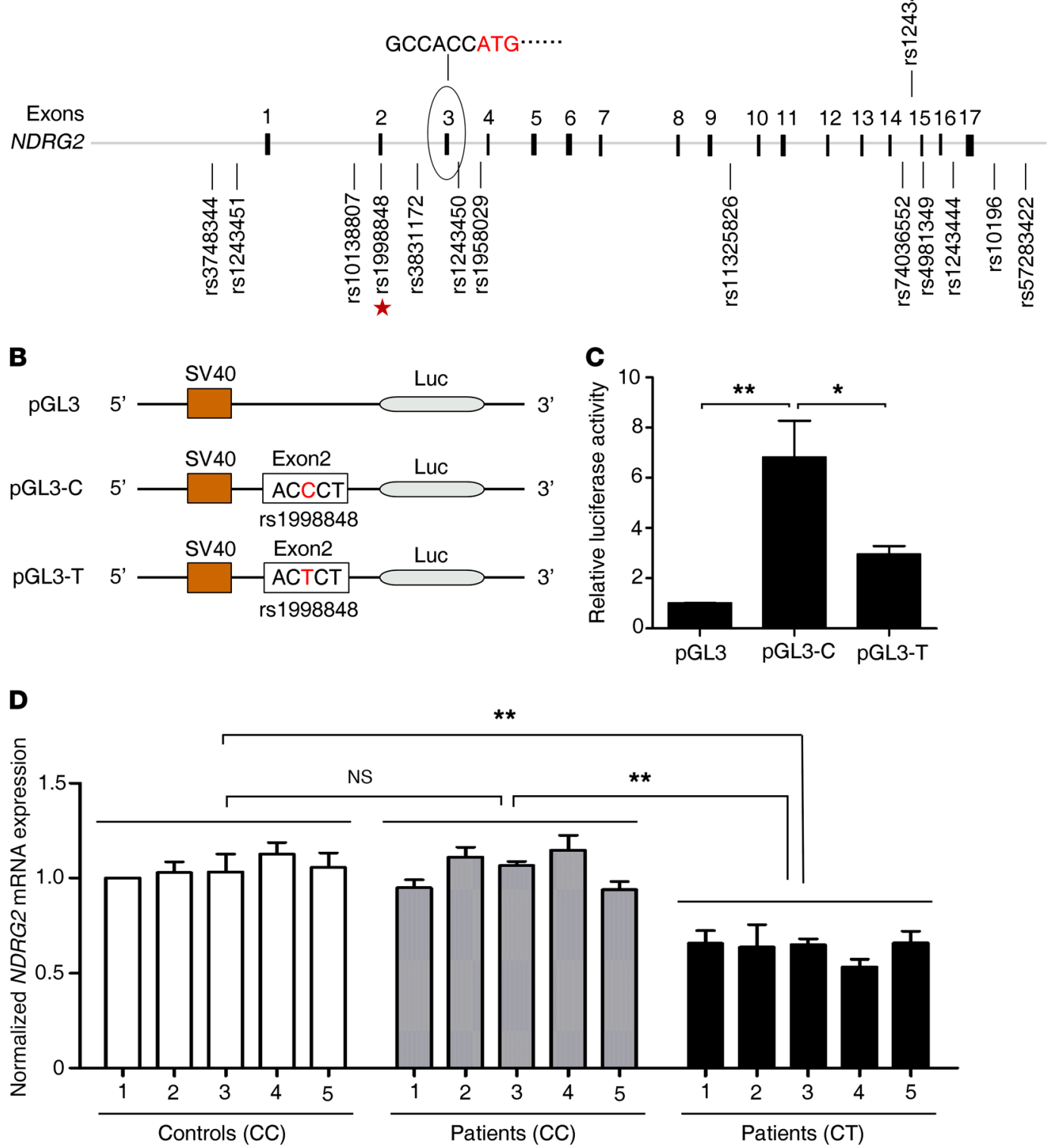

Figure 6. SNP rs1998848 in NDRG2 exon 2 is associated with susceptibility to ADHD and suppression of NDRG2 expression. (A) Fourteen polymorphic SNPs in a 10-kb region containing the NDRG2 gene. The rs1998848 SNP in exon 2 (star) is the only SNP associated with ADHD susceptibility. The numbers indicate the exon sequence. The open reading frame is located in exon 3. (B) The NDRG2 promoter, exon 1, and exon 2 with the major allele $C$ (pGL3-C) or minor allele T (pGL3-T) of rs1998848 were inserted upstream of the luciferase reporter gene. The pGL3-basic vector (pGL3) was used as a negative control. (C) The relative luciferase activity (firefly luciferase/Renilla luciferase) of pGL3-C, pGL3-T, or pGL3 was analyzed in HEK293 cells. Luciferase activity experiments were performed in triplicate, and data were obtained from 3 independent measurements. ${ }^{*} P<0.05 ;{ }^{*} P<0.01,1$-way ANOVA with Tukey-Kramer post hoc test. Error bars indicate mean \pm SEM. (D) Relative levels of NDRG2 mRNA in the peripheral blood cells of the heterozygous (CT) patients (5 cases), homozygous (CC) patients (5 cases), and homozygous controls (5 cases). The values were normalized to $\beta$-actin, and control 1 was designated 1. Data were obtained from 3 independent measurements, and each experiment was performed in quadruplicate. ${ }^{* *} P<0.01,1$-way ANOVA with the Tukey-Kramer post hoc test. Error bars indicate mean $\pm \mathrm{SEM}$.

In addition, there were no differences in the expression levels of EAAT1/2 and $\mathrm{Na}^{+} / \mathrm{K}^{+}$-ATPase $\alpha 1 / \beta 1$ between day and night (Supplemental Figure 16). There is substantial evidence that glutamate release peaks at night in the mouse brain, which is consistent with mouse behavioral rhythms $(23,24)$. These results suggest that the increase in glutamate release during the night underlies the significantly enhanced locomotor activity in the $\mathrm{Ndrg}^{-{ }^{--}}$mice at night (Supplemental Figure 3).
An NDRG2 peptide corrects ADHD-like behaviors in Ndrg2-mice. We constructed different NDRG2 deletion mutations to identify the region in NDRG2 that is required for binding and stabilizing $\mathrm{Na}^{+} / \mathrm{K}^{+}$-ATPase $\beta 1$. We found that a region encompassing aa residues 141-239 was critical for the interaction between NDRG2 and $\mathrm{Na}^{+} / \mathrm{K}^{+}$-ATPase $\beta 1$ (Figure $4, \mathrm{~A}-\mathrm{C}$ ). Next, we subdivided NDRG2 aa residues 141-239 into 5 fragments (Figure 4D) and synthesized 5 peptides containing human immunodeficiency virus-type 1 trans- 



Figure 7. Schematic representation of the dopaminergic deficit and astroglial glutamate clearance deficit hypotheses of ADHD. Left panel, dopaminergic deficit hypothesis. Most ADHD animal models favor the dopaminergic deficit hypothesis. The proposed impairments of the dopaminergic system include reduced dopamine synthesis, deficient formation and release of dopaminergic synaptic vesicles, dysfunction of inhibitory dopamine receptors, increased dopamine reuptake through dopamine transporters, and increased dopamine degradation by monoamine oxidase. Right panel, astroglial glutamate clearance deficit hypothesis. Here, we propose a new mechanism underlying the shift in the balance between excitation and inhibition in ADHD. In astrocytes, NDRG2 deficiency attenuates its interaction with $\mathrm{Na}^{+}$/ $\mathrm{K}^{+}-$ATPase $\beta 1$. The stability of $\mathrm{Na}^{+} / \mathrm{K}^{+}$-ATPase $\beta 1$ is decreased without the control of NDRG2. Subsequently, the unstable $\mathrm{Na}^{+} / \mathrm{K}^{+}$-ATPase $\beta 1$ fails to effectively generate a transmembrane $\mathrm{Na}^{+}$gradient together with $\mathrm{Na}^{+} / \mathrm{K}^{+}$-ATPase $\alpha 1$. The glutamate cleared by EAATs is cotransported with $\mathrm{Na}^{+}$into astrocytes. Therefore, the impaired transmembrane $\mathrm{Na}^{+}$gradient leads to reduced astroglial glutamate clearance and enhanced synaptic glutamate excitation. DOPA, dihydroxyphenylalanine; MAO, monoamine oxidase; DAT, dopamine transporter; DR, dopamine receptor.

activator of transcription (TAT), a tool that can deliver target peptides through the blood-brain barrier and cell membranes $(42,43)$.

Astrocytes treated with TAT-NDRG2(aa 141-160)-FITC $(20 \mu \mathrm{M})$ exhibited green fluorescence in their cytoplasm and processes, indicating intracellular peptide uptake (Supplemental Figure 17). TAT peptides can potentially cross the cellular membrane immediately, and TAT-NDRG2(aa 141-160)-FITC accumulation was detectable in astrocytes within 5 minutes of application (Supplemental Figure 17). We then examined the stability of the $\mathrm{Na}^{+} / \mathrm{K}^{+}$-ATPase $\beta 1$ protein after treating the $\mathrm{Ndrg}^{-}-$astrocytes with the NDRG2 peptides. TAT-control or TAT-NDRG2 peptides and emetine (a protein synthesis inhibitor) were simultaneously added to $\mathrm{Ndrg}^{-/-}$astrocytes, and cells were harvested at various time intervals. The halflife of $\mathrm{Na}^{+} / \mathrm{K}^{+}$-ATPase $\beta 1$ was much longer in the presence of TATNDRG2(aa 141-160) than with the TAT-control, TAT-NDRG2(aa 161-180), TAT-NDRG2(aa 181-200), TAT-NDRG2(aa 201-220), or TAT-NDRG2(aa 221-239) (Figure 4E and Supplemental Figure 18), indicating that aa residues 141-160 of NDRG2 are critical for the interaction with and stabilization of endogenous $\mathrm{Na}^{+} / \mathrm{K}^{+}-$ ATPase $\beta 1$. The proteinlevels of EAAT1/2 and $\mathrm{Na}^{+} / \mathrm{K}^{+}$-ATPase $\beta 1$ were also notably rescued after TAT-NDRG2(aa 141-160) treatment of $\mathrm{Ndrg}^{2-}$ astrocytes (Supplemental Figure 19A). In addition, the administration of the TAT-NDRG2(aa 141-160) significantly res- cued the rate and amount of glutamate clearance compared with the treatment with TAT-control peptide in the Ndrg2 ${ }^{--}$astrocytes (Figure $4 \mathrm{~F}$ ). In the WT astrocytes, neither the protein halflife of $\mathrm{Na}^{+} / \mathrm{K}^{+}$-ATPase $\beta 1$ (Supplemental Figure 20A) nor astroglial glutamate clearance (Supplemental Figure 20B) was significantly enhanced after $20 \mu \mathrm{M}$ TAT-NDRG2(aa 141-160) treatment. These results suggest that endogenous NDRG2 sufficiently bound and stabilized $\mathrm{Na}^{+} / \mathrm{K}^{+}$-ATPase $\beta 1$ in the WT astrocytes, while $20 \mu \mathrm{M}$ TAT-NDRG2 (aa 141-160) peptide lacked competitive binding with $\mathrm{Na}^{+} / \mathrm{K}^{+}$-ATPase $\beta 1$. However, the TAT-NDRG2(aa 141-160) peptide exhibited strong binding ability with $\mathrm{Na}^{+} / \mathrm{K}^{+}$-ATPase $\beta 1$ under NDRG2 deficiency conditions.

Next, we tested whether TATNDRG2(aa 141-160) could attenuate the increased excitation in the $\mathrm{Ndrg} 2^{-1-}$ mice. TAT-NDRG2(aa 141-160)-FITC was injected into $\mathrm{Ndrg}^{-/-}$mice through the subclavian vein. Peptide accumulation was detectable in the $\mathrm{Ndrg}^{-1}$ brains within 30 minutes of application, peaked at 2 hours, and remained detectable for 8 hours after injection (Supplemental Figure 21A). TAT-NDRG2(aa 141-160)FITC could enter astrocytes (Supplemental Figure 21B) in different mouse brain regions. The protein levels of EAAT1 $/ 2$ and $\mathrm{Na}^{+} / \mathrm{K}^{+}$-ATPase $\beta 1$ were notably rescued in the $\mathrm{mPFC}$, hippocampus, and striatum in the $\mathrm{Ndrg}^{--}$mice 2 hours after TATNDRG2(aa 141-160) injection (Supplemental Figure 19B). Consistent with the increase in glutamate clearance in vitro, interstitial glutamate levels were remarkably reduced in the $\mathrm{Ndrg} 2^{--} \mathrm{mPFC}$, hippocampus, and striatum following TAT-NDRG2(aa 141-160) injection (Supplemental Figure 22). In addition, TAT-NDRG2(aa 141-160) treatment effectively reduced sEPSC amplitude in the $\mathrm{Ndrg}^{-/}$glutamatergic neurons (Figure 4G). These results further support the suppression of astroglial glutamate clearance as a mechanism for elevated excitation in the $\mathrm{Ndrg}^{--}{ }^{-}$brain.

Finally, we sought to determine whether the NDRG2 peptide-induced enhancement of astroglial glutamate clearance could rescue ADHD-like behaviors in the $\mathrm{Ndrg}^{--}$mice. As a result, TAT-NDRG2(aa 141-160) injection substantially mitigated the hyperactivity of the $\mathrm{Ndrg}^{--}$mice (Figure 5, A and B, and Supplemental Figure 23). Furthermore, TAT-NDRG2(aa 141-160) injection reversed the distractibility and impulsivity of the $\mathrm{Ndrg} 2^{-1-}$ mice (Figure 5, C and D). However, we did not observe an amelioration of the memory impairment in the $\mathrm{Ndrg}^{--}$mice after treatment with the NDRG2 peptide (Figure 5, E-G). Similar to the NDRG2 peptide-induced reductions in behavioral abnormalities, the administration of the TAT-NDRG2(aa 141-160) peptide sig- 


\begin{tabular}{|c|c|c|c|c|}
\hline Variable & $\begin{array}{l}\text { Control } \\
\text { group }\end{array}$ & $\begin{array}{l}\text { ADHD } \\
\text { group }\end{array}$ & $\begin{array}{c}\text { OR } \\
(95 \% \mathrm{Cl})\end{array}$ & $P$ value \\
\hline Cohort 1 & $n=82$ & $n=70$ & & \\
\hline Age, mean $\pm S D, y r$ & $9.0 \pm 1.9$ & $9.3 \pm 1.9$ & & $0.572^{\mathrm{A}}$ \\
\hline \multicolumn{5}{|l|}{ Sex } \\
\hline Male & $62(75.6 \%)$ & $53(75.7 \%)$ & $0.994(0.473-2.091)$ & $0.988^{\mathrm{B}}$ \\
\hline Female & $20(24.4 \%)$ & $17(24.3 \%)$ & & \\
\hline \multicolumn{5}{|l|}{ Genotype } \\
\hline CT & $4(4.9 \%)$ & $17(24.3 \%)$ & 6.255 (1.993-19.630) & $0.001^{c}$ \\
\hline СС & 78 (95.1\%) & $53(75.7 \%)$ & & \\
\hline Cohort 2 & $n=80$ & $n=81$ & & \\
\hline Age, mean \pm SD, yr & $8.2 \pm 1.7$ & $8.4 \pm 1.8$ & & $0.470^{A}$ \\
\hline \multicolumn{5}{|l|}{ Sex } \\
\hline Male & $61(76.2 \%)$ & $68(84.0 \%)$ & $0.614(0.280-1.346)$ & $0.242^{\mathrm{B}}$ \\
\hline Female & $19(23.8 \%)$ & $13(16.0 \%)$ & & \\
\hline \multicolumn{5}{|l|}{ Genotype } \\
\hline CT & $2(2.5 \%)$ & $14(17.3 \%)$ & $8.149(1.787-37.154)$ & $0.003^{c}$ \\
\hline СС & 78 (97.5\%) & $67(82.7 \%)$ & & \\
\hline
\end{tabular}

${ }^{A}$ Student's $t$ test. ${ }^{B} \chi^{2}$ test. 'Logistic regression analysis after adjusting for sex. OR, odds ratio.

nificantly reduced the aberrant $\theta$ EEG rhythms in the $\mathrm{Ndrg} 2^{-/-}$mice (Figure 5, H and I). These results indicate that the TAT-NDRG2 (aa 141-160) peptide is an effective treatment for ADHD-like symptoms in the $\mathrm{Ndrg} 2^{-/-}$mice.

A SNP in the NDRG2 gene is associated with ADHD in children. To determine whether NDRG2 deficiency is associated with the development of ADHD in humans, we genotyped the NDRG2 gene on chromosome 14q11.2 in 2 independent cohorts of Chinese children (a total of 151 patients with sporadic ADHD and 162 controls). The subjects with ADHD and the controls were age- and sex-matched (Table 1). We verified that 14 SNPs located in NDRG2 from the dbSNP database were indeed polymorphic (Figure 6A). However, only one of these SNPs, rs1998848, was associated with ADHD susceptibility after Bonferroni's correction. Compared with the homozygous genotype (CC), the heterozygous genotype (CT) was more strongly associated with increased risk of ADHD (cohort 1: 6.3-fold; cohort 2: 8.1-fold) (Table 1).

Because rs 1998848 is located in exon 2 of NDRG2, immediately before the open reading frame located in exon 3 , we speculated that rs1998848 plays a functional role in NDRG2 expression. To test this hypothesis, we constructed a luciferase reporter plasmid by inserting the 1,168-bp promoter, exon 1, and exon 2 sequences of the NDRG2 gene carrying the C or T residue of rs1998848 upstream of the luciferase gene (Figure 6B). We observed a greater than 6-fold increase in luciferase activity in cells expressing the major allele $(\mathrm{C})$ sequence and an approximately 2-fold increase in luciferase activity in cells expressing the minor allele $(\mathrm{T})$ sequence compared with the levels of the empty control (Figure 6C). In addition, compared with homozygous genotype (CC) patients and homozygous genotype (CC) controls, the mRNA levels of NDRG2 in the peripheral blood cells of heterozygous genotype $(\mathrm{CT})$ patients were significantly decreased
(Figure 6D). These results suggest that NDRG2 expression is affected by rs1998848, with the ADHD susceptibility-associated minor allele contributing to a reduction in NDRG2 expression.

\section{Discussion}

This study is the first, to our knowledge, to demonstrate that a deficiency of NDRG2, a known tumor suppressor $(16,17)$, leads to a canonical ADHD-like phenotype, including hyperactivity, impulsivity, attention deficits, and impaired memory, which meet the face validity criteria for ADHD animal models (28, 29, 44, 45). Increased interstitial glutamate levels and excitatory transmission underlie the behavioral abnormalities in $\mathrm{Ndrg}^{-/-}$mice. In addition, an NDRG2 SNP, rs1998848, is associated with the risk of ADHD in children.

The dopamine deficit theory of ADHD (29, 46-50) (Figure 7) has been studied extensively in patients with $\operatorname{ADHD}(51,52)$ and is consistent with hypodopaminergic rodent models of ADHD (6). Methylphenidate, which exerts its effects by increasing synaptic dopamine levels through inhibition of dopamine transportermediated dopamine reuptake (53), has been used to treat ADHD in children and adults for many years (54). Unexpectedly, we did not observe a rescuing effect of methylphenidate on the hyperactivity of the $\mathrm{Ndrg}^{---}$mice. Thus, we speculate that a dopamineindependent mechanism is responsible for the behavioral abnormalities of the $\mathrm{Ndrg2^{-/- }}$ mice.

Alterations in the excitation-inhibition balance have been suggested to be core mechanisms of $\operatorname{ADHD}(28,55)$. The levels of the inhibitory neurotransmitter GABA and biogenic amines, including dopamine, norepinephrine, and serotonin in the interstitial fluid, were similar between the WT and $\mathrm{Ndrg}^{-{ }^{--}}$brains, whereas the interstitial levels of 2 excitatory neurotransmitters, glutamate and aspartate, exhibited a substantial increase in the $\mathrm{Ndrg} 2^{-/-}$mice. A current view of the dopamine/glutamate relationship is that increased extrasynaptic dopamine is required to suppress glutamate release by activating dopamine receptors in the striatum (56). However, our data suggest that enhanced interstitial glutamate and excitatory responses are independent of dopamine in $\mathrm{Ndrg} 2^{-/-}$mice.

Glutamate is the primary neurotransmitter involved in regulating excitatory synapses (57). We further detected increased sEPSC amplitude in the $\mathrm{Ndrg}^{--}$CA1 pyramidal neurons, suggesting that elevated interstitial glutamate levels underlie the enhanced excitation. Excitatory glutamatergic system dysfunction plays an important role in the pathogenesis of neuropsychiatric disorders (58-62). A few studies have investigated the role of glutamate in the context of $\operatorname{ADHD}(63,64)$, although their conclusions are not completely consistent. A recent study observed a notable increase in regional glutamate levels in a spontaneously hyperactive rat model of ADHD (65). However, the key molecules and precise mechanism underlying the involvement of glutamate in ADHD are largely unknown.

We previously found that $\mathrm{Na}^{+} / \mathrm{K}^{+}$-ATPase $\beta 1$ interacted with NDRG2 in a yeast 2-hybrid system (39). $\mathrm{Na}^{+} / \mathrm{K}^{+}$-ATPase $\beta 1$, a regulatory subunit of $\mathrm{Na}^{+} / \mathrm{K}^{+}$-ATPase, is critical for sodiumdependent glutamate uptake into astrocytes (66). Here, we found that NDRG2 was required for astroglial glutamate clearance by regulating glutamate transporters (EAATs) through an interaction with $\mathrm{Na}^{+} / \mathrm{K}^{+}$-ATPase $\beta 1$. Therefore, NDRG2 deficiency impairs 
astroglial glutamate clearance and shifts the balance between excitation and inhibition (Figure 7).

Additionally, we screened an NDRG2 peptide to rescue the function of $\mathrm{Na}^{+} / \mathrm{K}^{+}$-ATPase $\beta 1$ in the $\mathrm{Ndrg}^{-/-}$astrocytes. This peptide effectively reversed the hyperactivity, impaired attention, and impulsivity observed in the $\mathrm{Ndrg} 2^{-/-}$mice. However, the peptide treatment did not rescue the memory deficits of the $\mathrm{Ndrg} 2^{---}$mice, suggesting that impaired memory may be caused by mechanisms unrelated to enhanced glutamate excitation. Future experiments should explore the medication efficacy of the NDRG2 peptide in other ADHD animal models. The spontaneously hyperactive rat model of ADHD would be an ideal animal model in which to test the intervention effect of the TAT-NDRG2(aa 141-160) peptide because this model showed an increase in evoked glutamate release in the PFC and striatum (65).

There is substantial molecular epidemiological evidence showing an association between candidate gene SNPs and the pathogenesis of ADHD (67-69). Most ADHD clinical studies have been conducted in the United States and Europe. However, there is comparable ADHD morbidity in Asia (70-72). In this study, we identified an association between rs1998848 and ADHD susceptibility in 2 independent cohorts of Chinese children (a total of 151 patients with ADHD and 162 controls) by identifying and analyzing SNPs in the NDRG2 gene located on chromosome 14q11.2. Heterozygosity for rs1998848 led to a reduction in NDRG2 expression and an increase in ADHD risk compared with the homozygous genotype. Concordantly, a previous report using a genomewide linkage analysis showed that Dutch patients with ADHD had an abnormal haplotype at 14q11.2 (15). Human NDRG2 heterozygosity at the rs1998848 SNP was associated with increased ADHD risk and decreased NDRG2 expression, which suggests that $\mathrm{Ndrg} 2^{+/-}$mice might exhibit ADHD-like behaviors. However, $\mathrm{Ndrg} 2^{+/-}$mice showed normal locomotor activity. This difference between humans and mice might be attributed to differences in the compensative capacity for protein deficiency.

In summary, we identified an association between NDRG2 and ADHD development and showed that astroglial NDRG2 regulates interstitial glutamate levels and maintains the excitatory-

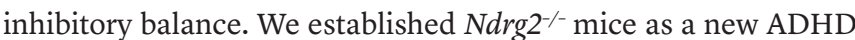
animal model and revealed a unique mechanism of ADHD that is distinct from the hypodopaminergic theory. The activation of astroglial glutamate clearance with the NDRG2 peptide provides a potential alternative therapeutic option for patients with ADHD who do not respond to methylphenidate treatment.

\section{Methods}

Generation of $\mathrm{Ndrg}^{-/-}$mice. The animals were housed in groups in a specific pathogen-free, temperature-controlled facility on a regular 12-hour light/12-hour dark cycle, with ad libitum access to food and water. $N d r g 2^{f / f l}$ mice (a gift of Libo Yao, Fourth Military Medical University) were crossed to B6.C- $\mathrm{Tg}(\mathrm{CMV}$-cre) $1 \mathrm{Cgn} / \mathrm{J}$ mice (Jackson Laboratory) to generate $\mathrm{Ndrg} 2^{-/-}$mice. The line was backcrossed to C57BL/6 J minimum of 8 times before use in any experiments in this study. Heterozygous mice carrying the knockout mutation were interbred to obtain the homozygous Ndrg2-deficient mice and their WT littermates (Supplemental Figure 1). Young (2 months) and old (8 and 12 months) male mice were used in this study unless otherwise specified.
Open-field test. The open-field test involved a plastic square box measuring $40 \mathrm{~cm} \times 40 \mathrm{~cm} \times 45 \mathrm{~cm}$, and the center zone line was located $6.5 \mathrm{~cm}$ away from the edge. The mice were transferred to the behavioral experiment room 1 hour before the test. We recorded mouse movements using a video tracking system (ANY-maze, Stoelting Co.) for 30 minutes and evaluated the total distance traveled, number of lines crossed, and moving velocity of the mice during the 30 minutes. The amount of time that mice spent in the center region of the open field was calculated in the initial 5 minutes of the test. After the completion of each trial, the mouse was returned to its home cage, and the field was cleaned with $30 \%$ ethanol. All behavioral procedures were performed between 1800 and 2000 hours.

5-CSRTT. Mice were restricted to $1 \mathrm{~g}$ of food per $10 \mathrm{~g}$ body weight until they reached $85 \%-90 \%$ of their free-feeding weight. Mice were trained in a test box to build the conditioned reflex between correct responses following the nose-poke stimulation and reward (a 15\% sucrose solution). The experimental procedures were performed using previously described methods $(25,26)$, with a slight modification to the training sessions (Supplemental Table 1). The percentages of accurate, premature, and omission responses were determined as follows: percentage of accurate responses $=$ number of correct responses/(number of correct responses + number of incorrect responses + number of premature responses + number of trials with no responses); percentage of premature responses $=$ number of premature responses $/$ (number of correct responses + number of incorrect responses + number of premature responses + number of trials with no responses); percentage of omission responses $=$ number of trials with no responses/(number of correct responses + number of incorrect responses + number of premature responses + number of trials with no responses).

Novel object recognition. Object memory was measured in an open-field apparatus $(40 \times 40 \times 45 \mathrm{~cm})$. All mice were transferred to the behavioral room 1 hour before the test. On day 1 , the mice were allowed to acclimate to the empty chamber for 10 minutes. On day 2, the mice were introduced to 2 identical objects in the chamber and allowed to explore freely, familiarizing themselves with the objects for 10 minutes; the mice were then returned to their home cages. The time the mice spent exploring each object was measured. During test 1 (1 hour later) and test 2 (24 hours later), 1 of the 2 identical objects was replaced with a differently shaped object and the time the mice spent exploring each object was measured (Supplemental Figure 6). Novel object preference was as follows: percentage $=$ time spent exploring the novel object/(time spent exploring the novel object + time spent exploring the familiar object). Object exploration was defined as each instance in which a mouse's nose touched the object or was oriented toward the object and came within $2 \mathrm{~cm}$ of it. Chewing the object or climbing onto the object did not qualify as exploration. A video tracking system (ANY-maze, Stoelting Co.) was used to generate heatmaps based on the exploration time.

EEG recordings. Mice were anesthetized with isoflurane, epidural electrodes were bilaterally implanted in the frontal lobe $(1.7 \mathrm{~mm}$ anterior to the bregma), and a separate ground electrode was installed in the occipital region of the skull. The animals were allowed to recover from the electrode implantation surgery for 7 days before the EEG recordings. EEG activities (filtered at $0.1-500 \mathrm{~Hz}$ ) were recorded for 30 minutes and amplified using PowerLab amplifiers (AD Instruments). The TAT-control or TAT-NDRG2(aa 141-160) peptide was intravenously injected into the mice 2 hours before the EEG recordings. The recorded traces were high- 
pass filtered $(3 \mathrm{~Hz})$ to analyze power spectral density. EEG spectral power was calculated in $0.25-\mathrm{Hz}$ bins using a 4 -second Hamming window.

Microdialysis. A microdialysis probe (4-mm guide cannula length, 0.22-mm membrane outer diameter, 1-mm membrane length, MW cutoff $50 \mathrm{kD}$; Eicom Corp.) was stereotaxically inserted into the $\mathrm{mPFC}$ ( $15^{\circ}$ angle, $1.75 \mathrm{~mm}$ anterior, $0.75 \mathrm{~mm}$ lateral from the bregma, and 1.5 $\mathrm{mm}$ ventral to the dura), the hippocampus ( $2.0 \mathrm{~mm}$ posterior, $1.2 \mathrm{~mm}$ lateral from the bregma, and $1.2 \mathrm{~mm}$ ventral to the dura), or the striatum (0.5 $\mathrm{mm}$ anterior, $2 \mathrm{~mm}$ lateral from bregma, and $4 \mathrm{~mm}$ ventral from dura) through the cannula guide. Artificial cerebrospinal fluid (ACSF) (124 mM NaCl; $4.4 \mathrm{mM} \mathrm{KCl} ; 2 \mathrm{mM} \mathrm{CaCl}_{2} ; 2 \mathrm{mM} \mathrm{MgSO}_{4} ; 25 \mathrm{mM}$ $\mathrm{NaHCO}_{3} ; 1 \mathrm{mM} \mathrm{KH}_{2} \mathrm{PO}_{4}$; and $10 \mathrm{mM}$ glucose; $\left.\mathrm{pH} 7.4\right)$ was perfused at a flow rate of $1 \mu \mathrm{l} / \mathrm{min}$ using a microinjection pump. The interstitial fluid in the mouse brains was continuously collected into microvials for 4 hours after 1 hour at equilibrium, and these microdialysis samples were subsequently lyophilized and redissolved in $20 \mu \mathrm{l}$ of ACSF.

HPLC analysis. The concentrations of glutamate, aspartate, GABA, dopamine, norepinephrine, and serotonin in the microdialysis samples were analyzed using HPLC (2695 Alliance HPLC, Waters). The microdialysis samples were precolumn derivatized with 2,4dinitrofluorobenzene for 30 minutes at $60^{\circ} \mathrm{C}$, and then $50 \mathrm{mM}$ potassium dihydrogen phosphate was added to each microdialysis sample mixture to stop the reaction. The microdialysis sample mixtures were then filtered using a $0.22-\mu \mathrm{m}$ filter. The mobile phase consisted of $50 \%$ acetonitrile and $40 \mathrm{mM} \mathrm{NaH} \mathrm{PO}_{4}(\mathrm{pH} \mathrm{8.0)}$ at a flow rate of $1.0 \mathrm{ml} / \mathrm{min}$. A UV detector was operated at an absorbance of $360 \mathrm{~nm}$ to analyze the neurotransmitter concentrations in the microdialysis samples. The concentrations were calculated using LCsolution software (Waters) based on standard samples (Sigma-Aldrich).

Electrophysiology. After the mice were anesthetized with isoflurane, transverse 400- $\mu \mathrm{m}$-thick brain slices were obtained. The slices were maintained in an incubation solution $(1.8 \mathrm{mM} \mathrm{KCl} ; 95 \mathrm{mM} \mathrm{NaCl}$; $0.5 \mathrm{mM} \mathrm{CaCl}_{2} ; 1.2 \mathrm{mM} \mathrm{KH}_{2} \mathrm{PO}_{4} ; 26 \mathrm{mM} \mathrm{NaHCO}_{3} ; 7 \mathrm{mM} \mathrm{MgSO}$; 50 $\mathrm{mM}$ sucrose; and $15 \mathrm{mM}$ glucose; bubbled with $95 \% \mathrm{O}_{2}, 5 \% \mathrm{CO}_{2} ; \mathrm{pH}$ 7.4) for 2 hours at room temperature. A single slice was then transferred to a recording chamber and submerged within bubbled recording solution at a flow rate of $3 \mathrm{ml} / \mathrm{min}$ at room temperature. The recording solution was identical to the incubation solution, but without $\mathrm{Mg}^{2+}$ and sucrose. Whole-cell patch-clamp recordings were obtained with glass pipettes, which had a resistance of 2-3 $\mathrm{M} \Omega$. The pipettes were filled with an internal solution that consisted of the following: $125 \mathrm{mM}$ K-gluconate, $1.0 \mathrm{mM} \mathrm{CaCl}_{2}, 10 \mathrm{mM} \mathrm{NaCl}, 5 \mathrm{mM}$ EGTA, $2 \mathrm{mM} \mathrm{MgCl}$, $19 \mathrm{mM}$ HEPES, and $5 \mathrm{mM}$ Mg-ATP; pH 7.4; and $300 \mathrm{mM}$ mOsm. The electrophysiological properties of the recorded neurons were detected in voltage-clamp mode using an Axon 700B amplifier (Axon Instruments) and were analyzed with pClamp10.0 data acquisition software (Molecular Devices). The signals were low-pass filtered at $5 \mathrm{kHz}$, sampled at $10 \mathrm{kHz}$, and analyzed offline. The membrane potential was maintained at $-70 \mathrm{mV}$. For the peptide rescue experiments, $20 \mu \mathrm{M}$ TAT-control or TAT-NDRG2(aa 141-160) peptide was added to the incubation solution 2 hours before the recordings.

Primary astrocyte cultures. Primary astrocytes were obtained from the brains of 1- to 3-day-old mouse pups. The brains were minced and trypsinized (0.25\% trypsin-EDTA) to produce cell suspensions, which were then plated in poly-L-lysine-coated flasks in DMEM supplemented with $10 \%$ FBS. The flasks were stored in a humidified incubator at $37^{\circ} \mathrm{C}$ and $5 \% \mathrm{CO}_{2}$. The cells were fed with fresh medi- um every 3 days. When the cells reached confluence after 2 weeks, the flasks were shaken ( 200 to $220 \mathrm{rpm}$ at $37^{\circ} \mathrm{C}$ ) overnight to remove the microglia and oligodendrocytes. After shaking, the cultures comprised more than $95 \%$ astrocytes, as determined by immunofluorescent staining for GFAP. The cells were then subcultured into different dishes according to distinct protocols.

Evaluation of glutamate uptake. Glutamate clearance was measured with a colorimetric assay using the Glutamate Detection Kit (BioVision). First, $200 \mu \mathrm{M}$ glutamate was added to the astrocyte cultures. Next, $50 \mu \mathrm{l}$ of culture medium was transferred to a transparent 96-well microplate at each time point and then mixed with $100 \mu \mathrm{l}$ of reaction mix $(2 \mu \mathrm{l}$ glutamate enzyme mix, $8 \mu$ glutamate developer, and $90 \mu \mathrm{l}$ assay buffer). The cell culture medium mixture was incubated at $37^{\circ} \mathrm{C}$ for 45 minutes. The absorbance at a wavelength of $450 \mathrm{~nm}$ of this cell culture medium mixture was then recorded using a microplate reader. The glutamate concentrations in the medium at each time point were calculated from the standard curve of known glutamate levels.

Immunoblotting. Proteins were extracted from cells using a lysis buffer (150 mM NaCl; $50 \mathrm{mM}$ Tris; $1 \mathrm{mM}$ EDTA; $1 \mathrm{mM} \mathrm{Na} \mathrm{VO}_{4} ; 0.1 \%$ SDS; $1 \%$ NP-40; $0.5 \%$ sodium deoxycholate; and a proteinase inhibitor mixture). After centrifugation $\left(13,680 \mathrm{~g}, 20\right.$ minutes, $\left.4^{\circ} \mathrm{C}\right)$, the concentrations of the protein extracts in the supernatant were measured using a BCA Protein Assay Kit (Thermo Fisher Scientific). Equal amounts of protein samples (10-20 $\mu \mathrm{g})$ were then boiled and loaded onto $10 \%$ SDS-PAGE gels for electrophoresis. The proteins were transferred from the gels to a polyvinylidene difluoride membrane and immunoblotted with the indicated primary and secondary antibodies. The signals on the blots were enhanced with a Chemiluminescence Detection Reagent Kit (Thermo Fisher Scientific). The immunoreactive bands were visualized using a gel-imaging analysis system (ChemiDoc MP, Bio-Rad) and quantified with Image Lab software (Bio-Rad). Additional information regarding the antibodies used in this study is given in Supplemental Table 2. For the $\mathrm{Na}^{+} / \mathrm{K}^{+}$-ATPase $\beta 1$ half-life detection, before immunoblotting analysis, $20 \mu \mathrm{M}$ TATcontrol or TAT-NDRG2 peptides and $100 \mu \mathrm{M}$ emetine (a protein synthesis inhibitor) (73) were simultaneously added to the $\mathrm{Ndrg} 2^{-/-}$ astrocytes, and the cells were harvested at various time intervals.

Coimmunoprecipitation. The cells were incubated with a lysis buffer (50 mM Tris-HCl; $150 \mathrm{mM} \mathrm{NaCl}, 1 \%$ Lubrol; 5 mM EDTA; and protease inhibitor cocktail) for 30 minutes at $4^{\circ} \mathrm{C}$. After centrifugation (13,680 $g$, 30 minutes, $4^{\circ} \mathrm{C}$ ), the supernatant was collected and incubated with the specific antibodies and protein A/G Sepharose beads (Santa Cruz Biotechnology Inc.) overnight at $4^{\circ} \mathrm{C}$. The antibody/antigen/Sepharose bead complex was then washed 4 times with a wash buffer $(10 \mathrm{mM}$ Tris-HCl; 150 mM NaCl; 1 mM EDTA; 1 mM EGTA; 150 mM Triton $\mathrm{X}-100 ; 0.2 \mathrm{mM}$ sodium orthovanadate; and protease inhibitor mixture). Proteins were eluted and separated using SDS-PAGE for immunoblotting. See complete unedited blots in the supplemental material.

Virus infection. Cultured astrocytes were seeded in 6-well plates at a density of $1 \times 10^{6}$ cells/well and incubated until they reached approximately $80 \%$ confluence. An adenovirus expressing $\mathrm{Na}^{+} / \mathrm{K}^{+}$-ATPase $\beta 1$ or the negative control virus was added to astrocytes with serum-free DMEM and incubated for 2 hours. Subsequently, the medium was replaced with fresh DMEM supplemented with 10\% FBS and astrocytes were incubated for another 48 hours. Recombinant adenoviruses carrying $\mathrm{Na}^{+} / \mathrm{K}^{+}-$ ATPase $\beta 1$ and control virus were purchased from Genechem Co. 
Peptides. All the peptides in this study were synthesized by the Bankpeptide Biological Technology Company. The peptides were HPLC purified to $95 \%$ purity. All the peptides were stored in powder form and were freshly diluted to $20 \mu \mathrm{M}$ or $10 \mathrm{mg} / \mathrm{kg}(1 \mathrm{ml} / \mathrm{kg})$ for use in cell- or animal-based experiments, respectively. For the in vivo experiments, including behavioral tests, EEG analysis, and microdialysis, mice were injected via the subclavian vein with $10 \mathrm{mg} / \mathrm{kg}$ TAT-control or TAT-NDRG2(aa 141-160) peptide 2 hours before detection.

Subjects and clinical assessments. In this study, 2 independent human cohorts were analyzed for the association between the NDRG2 SNP and ADHD risk. In the first cohort, 152 subjects consisting of 70 patients with ADHD (53 male and 17 female, mean age 9.3 years) and 82 controls (62 male and 20 female, mean age 9.0 years) from Children's Hospital of Soochow University were assessed. In the second cohort, 161 subjects consisting of 81 patients with ADHD (68 male and 13 female, mean age 8.4 years) and 80 controls (61 male and 19 female, mean age 8.2 years) from Xijing Hospital were assessed. Patients who met the clinical Diagnostic and Statistical Manual of Mental Disorders, 4th edition (DSM-IV) criteria for ADHD were recruited from child psychiatry outpatient units. We excluded patients who were currently affected by or had a history of other psychiatric or neurological diseases. Children whose IQs were below 70 according to the Wechsler Intelligence Scale for Children (WISC-V, http://wiscv.com/) were also excluded. The ages and sexes of the patients with ADHD and controls were matched to avoid possible study bias (Table 1).

Genotyping of NDRG2 SNPs. Genomic DNA of patients and controls was extracted from peripheral blood using the DNeasy Blood \& Tissue Kit (QIAGEN). Genotyping was performed using a 3730xl DNA Analyzer (Applied Biosystems). The experimenters conducting the genotyping were blinded to the sample identities. The $5^{\prime}$ and $3^{\prime}$ flanking regions of the NDRG2 gene were arbitrarily set at 1,000 and 800 bp, respectively. The SNP details for the NDRG2 gene were retrieved from the dbSNP database (http://www.ncbi.nlm.nih.gov/SNP/). The genotype distribution of the SNPs in the controls was in accordance with Hardy-Weinberg equilibrium.

Luciferase activity. A 1,168-bp sequence containing the promoter, exon 1, and exon 2 of the NDRG 2 gene carrying the $\mathrm{C}$ or $\mathrm{T}$ residue of rs1998848 was synthesized and subcloned into the pGL3-basic reporter vector (Promega). HEK293 cells $\left(2 \times 10^{4}\right.$ cells/well) were placed in 96-well plates and cultured in DMEM with 10\% FBS overnight. When the cells reached $75 \%$ confluency, they were transfected with $0.1 \mu \mathrm{g}$ of the constructed pGL3 reporter vector and $0.005 \mu \mathrm{g}$ of pHRL (an internal control) using Lipofectamine 2000 (Thermo Fisher Scientific) and were incubated in this transfection mixture for 48 hours. Luciferase activity was measured using a GLOMAX 20/20 luminometer (Promega) with a Dual-Luciferase Reporter Assay System Kit (Promega).

Real-time PCR. RNA extracted from human peripheral blood cells with TRIzol reagent (Invitrogen, Life Technologies) was converted to cDNA with the RevertAid First Strand cDNA Synthesis Kit (Fermentas). Real-time PCR analysis was performed using the Applied Biosystems Prism 7500 Real-Time PCR Detection System (ABI) and the SYBR Premix Ex-Taq II Kit (Takara Bio Inc.) according to the manufacturers' instructions. The PCR reactions ( $25 \mu \mathrm{l} /$ tube, in triplicate) were first heated at $95^{\circ} \mathrm{C}$ for 10 seconds for denaturation and then were subjected to 35 cycles of $95^{\circ} \mathrm{C}$ for 5 seconds and $60^{\circ} \mathrm{C}$ for 34 seconds. The relative gene expression levels were calculated using the $2^{-\Delta \Delta C t}$ method, in which Ct represents the threshold cycle and $\beta$-actin was used as a reference gene. Specific primers were used to amplify human NDRG2 with the forward and reverse primer sequences GAGATATGCTCTTAACCACCCG and GCTGCCCAATCCATCCAA, respectively.

For further information, see Supplemental Methods.

Statistics. The data are represented as the median or mean \pm SEM unless otherwise specified. The statistical analyses were determined using a 2-tailed Student's $t$ test, Wilcoxon rank sum test, or 1-way ANOVA followed by the Tukey-Kramer post hoc test (GraphPad Prism 6.0 software) unless otherwise specified. For the clinical data, 2-tailed Student's $t$ test and the $\chi^{2}$ test were used to calculate age and sex differences, respectively. The associations of allele frequencies with ADHD susceptibility were assessed by logistic regression after adjusting for sex. Statistically significant differences were defined as $P<0.05$.

Study approval. The studies in animals were reviewed and approved by the Animal Care Committee of Fourth Military Medical University. All efforts were made to minimize the number of mice used and their suffering. The clinical study protocol was approved by the Ethics Committee of Xijing Hospital, Fourth Military Medical University (ID: KY20172006-1), and was registered at ClinicalTrials. gov (ID: NCT03018574). Informed consent was obtained from the subjects prior to their participation in the study.

\section{Author contributions}

LX, YL, SW, and HD conceived of and designed the study. YL, AY, $\mathrm{XS}$, and MZ performed most of the experiments. JZ was responsible for the genotyping of patients with ADHD and the data analysis. RX conducted the electrophysiological recordings and analysis of the sEPSCs. WL performed the EEG recordings and analysis. ZF conducted all immunofluorescence experiments. YZ performed all immunoblotting experiments. PW and HW collected blood samples of the ADHD patients and controls. YL prepared most of the figures. LX and YL initiated the project and wrote the manuscript.

\section{Acknowledgments}

We thank many of our colleagues at the Fourth Military Medical University: Yuhai Zhang in the Department of Health Statistics for providing assistance with the statistical analysis; Aidong Wen and Qi Yang in the Department of Pharmacy for providing technical assistance with the HPLC analysis; Haopeng Zhang and Liang Tao in the Department of Anesthesiology for providing assistance with the animal behavioral tests; and Ting Gu in the Department of Anesthesiology for her kind assistance in isolating the primary astrocytes. We also thank Guangzhou Sagene Biotech Co. for drawing the schematic. The present study was supported by the National Natural Science Foundation of China (81420108013 to LX; 81471110, 81671184 to YL), the National Key Technology Research and Development Program of the Ministry of Science and Technology of China (2012BAI11B02 to LX) and the National Basic Research Program of China (2014CB543202 to LX).

Address correspondence to: Lize Xiong or Yan Li, Department of Anesthesiology and Perioperative Medicine, Xijing Hospital, Fourth Military Medical University, 127 Changle West Road, Xi'an, Shaanxi Province, 710032, China. Phone: 86.0298.477.5012; Email: mzkxlz@126.com (L. Xiong); liyann@fmmu.edu.cn (Y. Li). 
1. Lichtenstein $P$, et al. Medication for attention deficit-hyperactivity disorder and criminality. N Engl J Med. 2012;367(21):2006-2014.

2. Dalsgaard S, Østergaard SD, Leckman JF, Mortensen PB, Pedersen MG. Mortality in children, adolescents, and adults with attention deficit hyperactivity disorder: a nationwide cohort study. Lancet. 2015;385(9983):2190-2196.

3. Thapar A, Cooper M. Attention deficit hyperactivity disorder. Lancet. 2016;387(10024):1240-1250.

4. Kendall T, Taylor E, Perez A, Taylor C, Guideline Development Group. Diagnosis and management of attention-deficit/hyperactivity disorder in children, young people, and adults: summary of NICE guidance. BMJ. 2008;337:a1239.

5. Swanson JM, et al. Etiologic subtypes of attentiondeficit/hyperactivity disorder: brain imaging, molecular genetic and environmental factors and the dopamine hypothesis. Neuropsychol Rev. 2007;17(1):39-59.

6. van der Kooij MA, Glennon JC. Animal models concerning the role of dopamine in attentiondeficit hyperactivity disorder. Neurosci Biobehav Rev. 2007;31(4):597-618.

7. Arcos-Burgos M, et al. Attention-deficit/ hyperactivity disorder in a population isolate: linkage to loci at 4q13.2, 5q33.3,11q22, and 17p11. Am J Hum Genet. 2004;75(6):998-1014.

8. Franke B, Neale BM, Faraone SV. Genomewide association studies in ADHD. Hum Genet. 2009;126(1):13-50.

9. Coe BP, Girirajan S, Eichler EE. The genetic variability and commonality of neurodevelopmental disease. Am JMed Genet C Semin Med Genet. 2012;160C(2):118-129.

10. Zhou Y, et al. Mice with Shank3 mutations associated with ASD and schizophrenia display both shared and distinct defects. Neuron. 2016;89(1):147-162.

11. Cristino AS, et al. Neurodevelopmental and neuropsychiatric disorders represent an interconnected molecular system. Mol Psychiatry. 2014;19(3):294-301.

12. Zahir F, et al. Novel deletions of 14q11.2 associated with developmental delay, cognitive impairment and similar minor anomalies in three children. J Med Genet. 2007;44(9):556-561.

13. Arinami T, et al. Genomewide high-density SNP linkage analysis of 236 Japanese families supports the existence of schizophrenia susceptibility loci on chromosomes 1p, 14q, and 20p. Am J Hum Genet. 2005;77(6):937-944.

14. Prontera $\mathrm{P}$, et al. Recurrent $\sim 100 \mathrm{~Kb}$ microdeletion in the chromosomal region 14q11.2, involving CHD8 gene, is associated with autism and macrocephaly. Am JMed Genet A. 2014;164A(12):3137-3141.

15. Vegt $\mathrm{R}$, et al. Genome-wide linkage analysis in a Dutch multigenerational family with attention deficit hyperactivity disorder. Eur J Hum Genet. 2010;18(2):206-211.

16. Lin K, Yin A, Yao L, Li Y. N-myc downstreamregulated gene 2 in the nervous system: from expression pattern to function. Acta Biochim Biophys Sin (Shanghai). 2015;47(10):761-766.

17. Yao L, Zhang J, Liu X. NDRG2: a Myc-repressed gene involved in cancer and cell stress. Acta Biochim Biophys Sin (Shanghai). 2008;40(7):625-635.
18. Deng Y, et al. N-Myc downstream-regulated gene 2 (NDRG2) inhibits glioblastoma cell proliferation. Int J Cancer. 2003;106(3):342-347.

19. Flügge G, Araya-Callis C, Garea-Rodriguez E, Stadelmann-Nessler C, Fuchs E. NDRG2 as a marker protein for brain astrocytes. Cell Tissue Res. 2014;357(1):31-41.

20. Li Y, et al. Spatial-temporal expression of NDRG2 in rat brain after focal cerebral ischemia and reperfusion. Brain Res. 2011;1382:252-258.

21. Takarada-Iemata $\mathrm{M}$, et al. Deletion of $\mathrm{N}-\mathrm{myc}$ downstream-regulated gene 2 attenuates reactive astrogliosis and inflammatory response in a mouse model of cortical stab injury. J Neurochem. 2014;130(3):374-387.

22. Mitchelmore C, Büchmann-Møller S, Rask L, West MJ, Troncoso JC, Jensen NA. NDRG2: a novel Alzheimer's disease associated protein. Neurobiol Dis. 2004;16(1):48-58.

23. Ripperger JA, Jud C, Albrecht U. The daily rhythm of mice. FEBS Lett. 2011;585(10):1384-1392.

24. Mintz EM, Marvel CL, Gillespie CF, Price KM, Albers HE. Activation of NMDA receptors in the suprachiasmatic nucleus produces light-like phase shifts of the circadian clock in vivo. J Neurosci. 1999;19(12):5124-5130.

25. Bari A, Dalley JW, Robbins TW. The application of the 5-choice serial reaction time task for the assessment of visual attentional processes and impulse control in rats. Nat Protoc. 2008;3(5):759-767.

26. Kim H, Ährlund-Richter S, Wang X, Deisseroth $\mathrm{K}$, Carlén M. Prefrontal parvalbumin neurons in control of attention. Cell. 2016;164(1-2):208-218

27. Russell VA. Reprint of "Neurobiology of animal models of attention-deficit hyperactivity disorder". J Neurosci Methods. 2007;166(2):I-XIV.

28. Won H, et al. GIT1 is associated with ADHD in humans and ADHD-like behaviors in mice. Nat Med. 2011;17(5):566-572.

29. Huang J, et al. Circadian modulation of dopamine levels and dopaminergic neuron development contributes to attention deficiency and hyperactive behavior. J Neurosci. 2015;35(6):2572-2587.

30. Pastor PN, Reuben CA. Diagnosed attention deficit hyperactivity disorder and learning disability: United States, 2004-2006. Vital Health Stat 10 2008;10(237):1-14.

31. Killeen PR, Russell VA, Sergeant JA. A behavioral neuroenergetics theory of ADHD. Neurosci Biobehav Rev. 2013;37(4):625-657.

32. Bonvicini C, Faraone SV, Scassellati C. Attentiondeficit hyperactivity disorder in adults: A systematic review and meta-analysis of genetic, pharmacogenetic and biochemical studies. Mol Psychiatry. 2016;21(7):872-884.

33. Faraone SV, Buitelaar J. Comparing the efficacy of stimulants for ADHD in children and adolescents using meta-analysis. Eur Child Adolesc Psychiatry. 2010;19(4):353-364.

34. Park S, et al. Baseline severity of parent-perceived inattentiveness is predictive of the difference between subjective and objective methylphenidate responses in children with attention-deficit/ hyperactivity disorder. JChild Adolesc Psychopharmacol. 2013;23(6):410-414.

35. de Sonneville LM, Njiokiktjien C, Bos H. Methylphenidate and information processing. Part 1:
Differentiation between responders and nonresponders; Part 2: Efficacy in responders. J Clin Exp Neuropsychol.1994;16(6):877-897.

36. Barry RJ, Clarke AR, Johnstone SJ. A review of electrophysiology in attention-deficit/hyperactivity disorder: I. Qualitative and quantitative electroencephalography. Clin Neurophysiol. 2003;114(2):171-183.

37. Rothstein JD, et al. Localization of neuronal and glial glutamate transporters. Neuron. 1994;13(3):713-725.

38. Zerangue N, Kavanaugh MP. Flux coupling in a neuronal glutamate transporter. Nature. 1996;383(6601):634-637.

39. Li Y, et al. N-myc downstream-regulated gene 2 , a novel estrogen-targeted gene, is involved in the regulation of $\mathrm{Na}+/ \mathrm{K}+-\mathrm{ATPase}$.J Biol Chem. 2011;286(37):32289-32299.

40. Rose EM, Koo JC, Antflick JE, Ahmed SM, Angers S, Hampson DR. Glutamate transporter coupling to Na,K-ATPase. J Neurosci. 2009;29(25):8143-8155.

41. Illarionova NB, Illarionava NB, Brismar $\mathrm{H}$, Aperia A, Gunnarson E. Role of Na,K-ATPase $\alpha 1$ and $\alpha 2$ isoforms in the support of astrocyte glutamate uptake. PLoS One. 2014;9(6):e98469.

42. Fan X, Jin WY, Lu J, Wang J, Wang YT. Rapid and reversible knockdown of endogenous proteins by peptide-directed lysosomal degradation. Nat Neurosci. 2014;17(3):471-480.

43. Vivès E, Brodin P, Lebleu B. A truncated HIV-1 Tat protein basic domain rapidly translocates through the plasma membrane and accumulates in the cell nucleus. J Biol Chem. 1997;272(25):16010-16017.

44. Wells MF, Wimmer RD, Schmitt LI, Feng G, Halassa MM. Thalamic reticular impairment underlies attention deficit in Ptchd1(Y/-) mice. Nature. 2016;532(7597):58-63.

45. Gong R, et al. Role for the membrane receptor guanylyl cyclase- $\mathrm{C}$ in attention deficiency and hyperactive behavior. Science. 2011;333(6049):1642-1646.

46. Avale ME, Falzone TL, Gelman DM, Low MJ, Grandy DK, Rubinstein M. The dopamine D4 receptor is essential for hyperactivity and impaired behavioral inhibition in a mouse mode of attention deficit/hyperactivity disorder. $\mathrm{Mol}$ Psychiatry. 2004;9(7):718-726.

47. Ettinger U, Merten N, Kambeitz J. Meta-analysis of the association of the SLC6A3 3'-UTR VNTR with cognition. Neurosci Biobehav Rev. 2016;60:72-81

48. Bartl J, et al. Effects of methylphenidate: the cellular point of view. Atten Defic Hyperact Disord. 2010;2(4):225-232.

49. Baek DJ, Lee CB, Baek SS. Effect of treadmill exercise on social interaction and tyrosine hydroxylase expression in the attentiondeficit/ hyperactivity disorder rats. J Exerc Rehabil. 2014;10(5):252-257.

50. Volz TJ, Farnsworth SJ, Hanson GR, Fleckenstein AE. Methylphenidate-induced alterations in synaptic vesicle trafficking and activity. Ann N $Y$ Acad Sci. 2008;1139:285-290.

51. Levy F. The dopamine theory of attention deficit hyperactivity disorder (ADHD). Aust N Z J Psychiatry. 1991;25(2):277-283.

52. Dougherty DD, Bonab AA, Spencer TJ, Rauch SL, 
Madras BK, Fischman AJ. Dopamine transporter density in patients with attention deficit hyperactivity disorder. Lancet. 1999;354(9196):2132-2133.

53. Calipari ES, Ferris MJ, Salahpour A, Caron MG, Jones SR. Methylphenidate amplifies the potency and reinforcing effects of amphetamines by increasing dopamine transporter expression. Nat Commun. 2013;4:2720.

54. Seeman P, Madras BK. Anti-hyperactivity medication: methylphenidate and amphetamine. $\mathrm{Mol}$ Psychiatry. 1998;3(5):386-396.

55. Edden RA, Crocetti D, Zhu H, Gilbert DL, Mostofsky SH. Reduced GABA concentration in attention-deficit/hyperactivity disorder. Arch Gen Psychiatry. 2012;69(7):750-753.

56. Russell VA. Dopamine hypofunction possibly results from a defect in glutamate-stimulated release of dopamine in the nucleus accumbens shell of a rat model for attention deficit hyperactivity disorder--the spontaneously hypertensive rat. Neurosci Biobehav Rev. 2003;27(7):671-682.

57. Erecińska M, Silver IA. Metabolism and role of glutamate in mammalian brain. Prog Neurobiol. 1990;35(4):245-296.

58. Field JR, Walker AG, Conn PJ. Targeting glutamate synapses in schizophrenia. Trends Mol Med. 2011;17(12):689-698.

59. Volk L, Chiu SL, Sharma K, Huganir RL. Glutamate synapses in human cognitive disorders. Annu Rev Neurosci. 2015;38:127-149.
60. Thompson SM, Kallarackal AJ, Kvarta MD, Van Dyke AM, LeGates TA, Cai X. An excitatory synapse hypothesis of depression. Trends Neurosci. 2015;38(5):279-294.

61. Javitt DC. Glutamate as a therapeutic target in psychiatric disorders. Mol Psychiatry. 2004;9(11):984-997, 979.

62. Tebartz van Elst L, et al. Disturbed cingulate glutamate metabolism in adults with high-functioning autism spectrum disorder: evidence in support of the excitatory/inhibitory imbalance hypothesis. Mol Psychiatry. 2014;19(12):1314-1325.

63. Bauer J, et al. Hyperactivity impulsivity in adult attention-deficit/hyperactivity disorder is related to glutamatergic dysfunction in the anterior cingulate cortex. World J Biol Psychiatry. https://doi.org/1 0.1080/15622975.2016.1262060.

64. Naaijen J, et al. Glutamatergic and GABAergic gene sets in attention-deficit/hyperactivity disorder: association to overlapping traits in ADHD and autism. Transl Psychiatry. 2017;7(1):e999.

65. Miller EM, Pomerleau F, Huettl P, Gerhardt GA, Glaser PE. Aberrant glutamate signaling in the prefrontal cortex and striatum of the spontaneously hypertensive rat model of attentiondeficit/hyperactivity disorder. Psychopharmacology (Berl). 2014;231(15):3019-3029.

66. Doğanli C, Oxvig C, Lykke-Hartmann K. Zebrafish as a novel model to assess $\mathrm{Na}+/ \mathrm{K}(+)$ ATPase-related neurological disorders. Neurosci Biobehav Rev. 2013;37(10 Pt 2):2774-2787.
67. Coghill DR, Seth S, Matthews K. A comprehensive assessment of memory, delay aversion, timing, inhibition, decision making and variability in attention deficit hyperactivity disorder: advancing beyond the three-pathway models. Psychol Med. 2014;44(9):1989-2001.

68. Coghill DR, Hayward D, Rhodes SM, Grimmer C, Matthews K. A longitudinal examination of neuropsychological and clinical functioning in boys with attention deficit hyperactivity disorder (ADHD): improvements in executive functioning do not explain clinical improvement. Psychol Med. 2014;44(5):1087-1099.

69. van Lieshout M, Luman M, Buitelaar J, Rommelse NN, Oosterlaan J. Does neurocognitive functioning predict future or persistence of ADHD? A systematic review. Clin Psychol Rev. 2013;33(4):539-560.

70. Anderson JC. Is childhood hyperactivity the product of western culture? Lancet. 1996;348(9020):73-74.

71. Choi TK, et al. Support for the MnlI polymorphism of SNAP25; a Korean ADHD case-control study. Mol Psychiatry. 2007;12(3):224-226.

72. Chen CK, et al. The dopamine transporter gene is associated with attention deficit hyperactivity disorder in a Taiwanese sample. Mol Psychiatry. 2003;8(4):393-396.

73. Jacoby DB, Engle JA, Towle HC. Induction of a rapidly responsive hepatic gene product by thyroid hormone requires ongoing protein synthesis. Mol Cell Biol. 1987;7(4):1352-1357. 